\title{
"A Study to Assess the Effectiveness Of Progressive Muscle Relaxation Therapy on Stress among Staff Nurses Working In Selected Hospitals at Vadodara City"
}

\author{
Ms.Palak Patel \\ (Department Of Mental Health Nursing,Sumandeep Nursing College/ Sumandeep Vidyapeeth University, \\ India)
}

\begin{abstract}
Stress is a multidimensional phenomenon which is focused on dynamic relationship between the individual and the environment. Studies indicated that medical professionals such as Medical students, Nurses and Nursing students experience many stressor agents. Hospitals are considered as one of the most stressful work environments, because there, it is the matter of humans' death and life. Nursing profession is generally perceived as a stressful and demanding profession. It is both physically and psychologically challenging. There are various methods recommended to control or reduce the stress. Progressive Muscle Relaxation Therapy is a systematic therapy for managing stress and achieving a deep state of relaxation. It is an effective and widely used strategy for stress relief. With regular practice it gives a complete relaxation .Pre experimental one group pre - test and post -test research design was adopted to achieve the goal of the study by using instrument i.e demographic data and stress assessment scale among 30 staff nurses. The findings of the study revealed that in pre test most of the nurses $53.3 \%$ had moderate stress, $40.0 \%$ had mild stress and $6.7 \%$ had severe stress. In post test most of the nurses had mild stress $73.3 \%$ and no stress $26.7 \%$. It is concluded that Progressive Muscle Relaxation Therapy is effective in reducing the stress level of the staff nurses.
\end{abstract}

Keywords: Hospital, Progressive Muscle Relaxation Therapy, Staff Nurses, Stress.

\subsection{Background Of The Study}

\section{Introduction}

"An Anxious Mind Can Not Exist In A Relaxed Body"-

Edmud Jacobson, MD

Stress is the emotional and physical strain caused as a result of our response to what happens around us.

Stress is a multidimensional phenomenon which is focused on dynamic relationship between the individual and the environment. It is also defined as a stressor, individual's response to the stimuli and interaction between the individual and the environment. It should be noted that some degree of stress can be effective on increasing and improving individuals' performance. Evidences indicate that most of the human successes are created in stressful conditions; but high rate of stress would followed by numerous consequences, including mental and physical illnesses, sleep disorders, restlessness, irritability, forgetfulness, abnormal fatigue, reduced individual's resistance and recurrent infections, headaches, poor concentration, memory impairment and reduce in problem solving ability. ${ }^{1}$

Studies indicated that medical professionals such as medical students, nurses and nursing students experience many stressor agents. ${ }^{2}$

Nurses and nursing students are influenced by the various hospital stressor agents in addition to the stress caused by theoretical training environment. Hospitals are considered as one of the most stressful work environments, because there, it is the matter of humans' death and life. ${ }^{3}$

The stress which is resulted from the environment can affect the way their personality develops and also cause the incidence of many undesirable behaviors in individual. ${ }^{3}$

Totally, theses stressor agents can be divided into three categories: category related to education, clinical, and socio individual factors. ${ }^{4}$ Various types of stress causes the reduction of individual's resistance through the negative effect which apply on the person's social and individual coping resources and in long-term can have unpleasant effects on individual's physical and mental health. It was indicated that stress can cause mental and physical illnesses, dysfunction and adjustment disorder and ultimately reduction of individuals' quality of life. ${ }^{5}$

A nurse is exposed to a variety of stress in her day to day life, medium levels of depersonalization to high levels of emotional exhaustion.

Stress is observed to be varying with other organizational variables such as structural, procedural and contextual factors. e.g. administrative support of nurses and nursing, Quality of nursing leadership; inter professional conflicts, constantly changing technology, or organizational restructuring. 
In a review of 68 articles on nurses' role stress Hancock, et al, U. S. A. in 2005, stated that the most frequently identified stressors were workload, role conflict, ambiguity, and lack of support from management and senior staff (Melissa Stoppler, 2005).

Nursing profession is generally perceived as a stressful and demanding profession. It is both physically and psychologically challenging.

There are various methods recommended to control or reduce the stress. ${ }^{8}$

Stress coping skills have a comprehensive concept and multiple cognitive-behavioral components. Generally, coping has been described as efforts to comply the individual with the environment or efforts for preventing from the negative consequences of stressful situation. Two main methods for preventing from stress are deal with problem-focused directly on the issue which includes direct activities on the environment in order to change or correction of the situation which is threatening and also emotion-focused practices which include thoughts or activities in order to control the unpleasant feelings which have been created from stressful conditions. Problem oriented therapys include active methods such as cognitive and behavioral problem solving. ${ }^{9}$

Cognitive-behavioral coping strategies are the most effective methods to reduce the stress. ${ }^{10}$

Considering that all the living organisms experience the stress, the aim of nursing is not removing the whole stress completely, because stress is part of the life. Response to stress can be in an unhealthy way, and the role of the nurse at this time is helping to promote the health. Health promotion includes strategies for reduction and management of the stress, the nurse also can use nursing process in order to manage the stress. ${ }^{11}$

Stress management practices include; yoga relaxation, progressive muscle relaxation, breathing exercises, meditation and mental imagery. ${ }^{12}$

A study findings indicated that stress symptoms were experienced by 100 per cent of staff nurses. Working experience, critically ill patients and environmental factors are contributing to the stress experienced by the nurses.

Progressive muscle relaxation therapy is a systematic therapy for managing stress and achieving a deep state of relaxation. that has been effectively used to control stress and anxiety relieve insomnia, and reduce symptoms of the stress. It is an effective and widely used strategy for stress relief. With regular practice, progressive muscle relaxation therapy gives a complete relaxation Dr. Edmund Jacobson (1930- 1975).

The progressive muscle relaxation Therapy leads to statistically significant changes in physiological stress and muscle conditions (Campos de Carvalho)

\subsection{Need For The Study}

WHO reports $50 \%$ employees in India Including nurses are under stress, $30 \%$ have problems of marital discord, $20 \%$ suffer from depression, $49 \%$ of people under stress say they suffer from upset stomach or nausea, $71 \%$ people under stress are not productive and cry regularly. UNESCO say's over $50 \%$ of children brought up in stressful conditions worldwide. Globally 1 out of every 10 students suffers significant distress. Over $50 \%$ of employee, lost workdays across the world are due to stress. The US government spends \$ 3 billion per year on stress related issues such as compensation claims, medical expenses and reduced productivity. India is spending very less amount while rate of prevailing is higher than USA. Shankaraiya (1984), Sulochana (2005) NIMHANS study says $36 \%$ professional nurses in Bangalore show signs of psychiatric disorder due to Job related stress.(2010)

Nurse patient ratio is never maintained in Gujarat

E.g. Mental health Institute- Ahmedabad Psychiatric Patients are specialized nursing need Group. It requires specific therapeutic nursing care so there should be 1:1 Nurse Patient ratio but you see 225 bedded hospital have only 27 staff nurse !!!!!

Nursing profession have multiple responsibilities.

Continues in the Public Vigilance - No personal space, Uncertainty, Insecurity, Anxiety, Stress, Lack of confidence, Lack of appraisal and reward, Over burden of workload, Timely bound task, Administrative responsibilities, Total responsibilities of the Patient, Hospitals and job of the other professionals.

No written guidelines, Confused Job charts, Nursing profession managed and administered by Medical profession.

Occupational hazards - Long hours shift duty, ever changing role, work with hazardous infection and chemicals. Abused and harassed by physicians to class-IV, No personal space. No power to protection from patient, No legal protection -one mistake can spoil job.- Job insecurity. Added by Family responsibility, Transportation, social and religious responsibility No support from superior or coworker, Less promotional opportunity, combined effect of all that hazards on health and alternatively falls in sickness, most nurses suffers from diseases of the stress and Anxiety, Thus stress is in the blood of nursing profession.

In reviewing stress and its consequences, in the stress coping strategies, the method of response to it would be more important than the nature of stress itself. The more appropriate method used in coping with 
stress, the less he/she would be damaged. ${ }^{7}$ There are various methods recommended to control or reduce the stress. ${ }^{8}$

For the goals of lowering professional stress and improved satisfaction, social support and improved team cooperation could protect nurses against burnout. ${ }^{13}$

Ibrahim Humaida (March 2012) studied" co-relation to examine the relationship between stress and psychosomatic complaints among nurses in a hospital at Tabarjal". The researcher selected 56 nurses working in hospital through the simple random sampling technique. Using the descriptive method the samples had requested to complete a questionnaire for rating of stress and the most common psychosomatic diseases. The results revealed that the stress was dominant among nurses, the prevalence of psychosomatic complaints was significantly higher in nursing profession, and there was significant correlation between stress and psychosomatic complaints among nurses. The study concluded as this research confirmed the effect of stress on the prevalence of psychosomatic symptoms among nurses. ${ }^{14}$

Karick H et al (September 2011) conducted an evidence-based empirical study on work characteristics among Nigerian nurses to determine how the roles and responsibilities associated with stress. 2245 Samples were studied. Nurses' empathy for and connection with patients demonstrates core professional values which are essential but, consequently, attract certain factors capable of inducing stress. Analyses showed levels of stress among Nigerian nurses experience medium to high levels of stress. Stress is varying with structural, procedural and contextual factors such as administrative support of nurses and nursing, inter and intra professional battles, and constantly changing technology. This study calls for further research into stress in the nurses. ${ }^{15}$

Derek Bryan (May 2013) reported in CAM Commons Evidence-Based Complementary And Alternative Medicine For The Twenty-First Century that Progressive muscle relaxation is a type of therapy used to help patients control the levels of tension in their muscles. Proponents of progressive muscle relaxation claim it is beneficial for the treatment of several physical and mental health conditions. These therapeutic theorists speculate that chronic muscular tension is a leading cause of most physical and mental ailments. While this notion is treated with scientific skepticism, there are a number of positive benefits that the technique can offer. ${ }^{16}$ Cathy Wong (2011) investigated "an experimental study on volunteers to compare effectiveness of progressive muscle relaxation technique against music therapy in USA." The researchers exposed volunteers to a stressful situation and then undergo progressive muscle relaxation technique or music therapy, or take part in a control group. Results revealed that members of progressive muscle relaxation group experienced greater relaxation including a more significant decrease in heart rate than the rest of the study members and helps soothe stress by reducing levels of hormone cortisone released in response to stress. ${ }^{17}$

Jose Rojan, D'Almeida (August 2013) conducted a study on, "Effectiveness of Jacobson's Progressive Muscle Relaxation (JPMR) on Blood Pressure and Health Related Stress Level among Patients with Hypertension in a Selected Hospital of Mangalore" The aim of the study is to assess the effectiveness of Jacobson's Progressive Muscle Relaxation (JPMR) on blood pressure and health related stress level among patients with hypertension. An evaluatory approach with one group pretest- post test design was done on a sample of 40 . JPMR was administered for 20 minutes to the patients for 4 days both in the morning and evening as 8 sessions. Pre and post intervention BP and health related stress was assessed, The mean systolic BP had reduced from $155.8 \pm 10.14$ to $121.7 \pm 4.47$ and mean diastolic BP had reduced from $92.7 \pm 4.52$ to $79.9 \pm 62.63$ after the administration of JPMR. The average reduction of systolic BP was $6.42 \mathrm{~mm}$ of $\mathrm{Hg}$ and that of diastolic $\mathrm{BP}$ was $0.8 \mathrm{~mm}$ of $\mathrm{Hg}$ over the 4 days. The mean health related stress level had reduced from $94.03 \pm 7.64$ to $62.8 \pm 7.15$, with a mean percentage reduction of $19.5 \%$. JPMR is a cost-effective, non-invasive, nonpharmacological alternative therapy in the management of stress and hypertension. ${ }^{18}$

\subsection{Statement Of Problem}

\section{"A Study To Assess The Effectiveness Of Progressive Muscle Relaxation Therapy On Level Of Stress} Among Staff Nurses Working In Selected Hospitals At Vadodara City."

\subsection{Objectives Of The Study}

$>\quad$ To assess the pre-test and post-test level of stress among staff nurses working in selected hospitals at vadodara city.

$>\quad$ To evaluate the effectiveness of the Progressive Muscles Relaxation Therapy on level of stress among staff nurses working in the selected Hospitals at vadodara city.

$>\quad$ To find out the association between the post test stress score with selected demographic variables.

\subsection{Hypothesis}

H1 - there will be significant difference in the level of stress before and after administering Progressive Muscle Relaxation Therapy among staff nurses working in selected hospitals at vadodara city. 
$\mathrm{H} 2$ - there will be significant association between level of post test stress of staff nurses with the selected demographic variables.

\subsection{Assumption}

$>\quad$ Staff nurse may be at risk for stress

$>\quad$ The environmental factors may play a major role in determining psychological well being of staff nurse.

The environmental factors may enhance positive or negative mental health among staff nurse.

\subsection{Operational Definitions}

Assess

D The statistical measurements of level of stress among staff nurses as determined by the stress assessment rating scale.

\section{Effectiveness}

The significant decrease in the level of stress among the staff nurses after administration of progressive muscles relaxation therapy as evidenced by the mean pre-test and post-test score.

\section{Progressive Muscles Relaxation Therapy}

Progressive muscles relaxation therapy can train staff nurse to reduce their stress levels by deliberately inducing relaxation in their muscles. The therapy relies on applying tension and relaxing that muscle group, progressing through all the muscle groups of the body to create a deep sense of calm.

Stress

D The word stress as a state of disequilibrium to an emotional or physical disturbance experienced by the staff nurses that occurs when there is a disharmony between demands occurring within an individual's demographic characteristics as an internal environment or working environment as an external environment and staff nurses' ability to cope with those demands.

\section{Staff Nurse}

$>\quad$ Staff Nurse - It means a registered nurse having minimum educational qualification is Basic B.Sc. Nursing and working with a designation of Staff Nurse in selected hospitals at Vadodara city.

\subsection{Conceptual Framework}

$>$ Conceptual framework is a group of related ideas, statements, or concepts which deals with concept that are assembled by the virtue of their relevance to a common theme. A conceptual model broadly presents an understanding of the phenomenon of interest and reflects the assumption and philosophic views of the model's designer.

The proposed study was aimed to assess the effectiveness of progressive muscle relaxation therapy on stress among staff nurses working in selected hospitals at vadodara city.

The Conceptual framework of the study was based on Ludwing Von Bertanloffy's General system theory. In 1968 Bertanloffy's introduce this theory as a universal theory that could be applied to many fields of study. ${ }^{19}$

According to Bertanloffy, General system theory provides a way of examining interrelationships and deriving principles. Theorist described human begin as an open system, for proper functioning of human being depends on the quality of its input, throughput, output and feedback. Being an open system, the client is capable of receiving information and gain knowledge from his environment. Utilizing this capacity of client, investigator takes the opportunity to provide information. The investigator examines whether the information is processed or not with the help of feedback.

Bertanloffy's model includes the following components.

System

System is connected, interdependent, interacting elements (E.g. components, people) that are hierarchically organized in to a single entity for the purpose of achieving a common goal. In the field of nursing, system can be an individual, a family or a community. These systems are always complex and are often studied as sub system.

In the present study, staff nurses working in hospitals of vadodara city are considered as a system. 


\section{Subsystem}

Subsystem is operationally defined as connected, interdependent, interacting elements that are part of large system.

In the present study, subsystem is staff nurses working in selected hospitals at vadodara city.

Input

Input consists of information, material or energy that enters the system.

In this study, an input includes selected socio demographic variable and existing level of stress among staff nurses working in selected hospitals at vadodara city. The pre-test questionnaire which is assessing the level of stress among staff nurses regarding various stressors like job design and workload, patient care, peer problems, problems related to supervisor/physician, uncertainity concerning treatment, miscellaneous etc. indicates the need for appropriate intervention.

\section{Through put} or process.

The system uses, organizes and transforms the information in between input and output is throughput

The present study try to evaluate the effectiveness of progressive muscle relaxation therapy on stress among staff nurses. by administering the progressive muscle relaxation therapy the investigator conduct the post -test and compare the results of pre and post test.

\section{Output}

Output is the transformed from of information, energy and matter that is given out by individual after processing. It is the evaluation phase.

The outcome of Progressive Muscle Relaxation Therapy is evaluated by stress scale. After post test, there will be significanant reduction in level of stress that indicates the effectiveness of Progressive Muscle Relaxation Therapy on Stress Among Staff Nurses.

\section{Feedback}

Feeedback refers to the process through which information is achieved at each stage of the system ,it also serves an input for the purpose of guiding and directing the system.

The feedback refers to the output that may be positive, negative or neutral. In this study, feedback measured in the output reveals the significant effectiveness or non effectiveness of the progressive muscle relaxation therapy on stress.

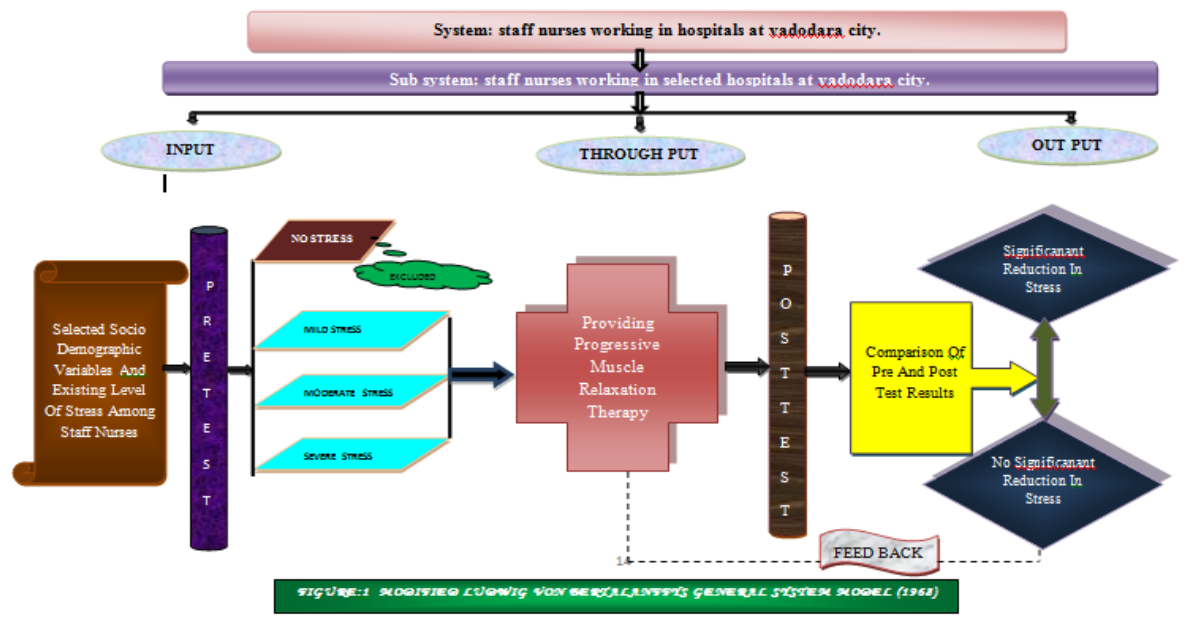

\subsection{Scope Of The Study}

Staff nurses are one of the occupation in which people working used to carry stress. Thus it is essential that all staff nurses understand how the progressive muscle relaxation therapy can help to reduce the stress. Lack of knowledge about stress management techniques can cause a high level of stress.

Scope of the present study:

$>\quad$ The study findings would throw light on the level of stress which the staff nurses having.

$>\quad$ The study could guide nurses regarding the useful and effectiveness of progressive muscle relaxation therapy. 


\section{Review Of Literature}

Literature review is key component of the research study. It is also a very important step of the research process. The literature review of this study has written in this chapter.

Literature review lays a systematic foundation for the research study. It explores and reveals the existing knowledge and information in the context of the present research study. Literature review in a specific area uncovers in depth information that provides support to the current research study. The explore information helps in designing the research study.

The literature review for the present study organized under the following headings.

1.1 Literature review related to stress among staff nurses

2.2 Literature review related to the effectiveness of the Progressive Muscle Relaxation Therapy

2.3 Literature review related to Progressive Muscle Relaxation Therapy and stress

\section{1 - Literature Review Related To Stress Among Staff Nurses}

Deependrasingh Kushwah (2011) had done" a descriptive study to assess occupation stress of the newly qualified staff nurses of government and private hospital influenced by selected demographic variable at Bangalore, Karnataka". The 60 newly qualified staff nurses selected by random sampling method. Sulivan stress assessment rating scale for nurses is used to assess the level of stress among nurses. Result shows nursing profession perceived as a physically and psychologically stressful. It is both challenging and demanding profession. There is a growing body of evidence, which validate that health care providers particularly nurses experience stress in the course of carrying out their work. ${ }^{20}$

M. Joy (2011) carried out "a comparative study to assess the level of occupational stress among staff nurses working in the day shift with that of night shift in selected hospitals was at Mangalore". 40 staff nurses each from day and night shift Sample for the study were selected by convenient sampling technique. Demographic data collection comprised age, sex, religion, marital status, psychiatric department area, income of family, residential area, years of experience and a structured questionnaire 50-item self-reports instrument had used to assess participant staff nurses' stress. The data of participants maintained in a daily log that described day-to-day stressors and how they coped with these. The study concluded, as there is significant association between level of occupational stress and selected demographic variables of staff nurses. ${ }^{21}$

Ningthoujam Monalisa Chanu (2011) had done" a study to assess the effectiveness of structured teaching programme on stress and coping among caregivers of hospitalised patients in a selected psychiatric hospital in Bangalore." The study had done on 50 caregivers of hospitalized patient at Spandana Hospitals, Nayandahalli at Bangalore. Pre and posttest assessment had done with five point rating scale to assess the level of stress among caregivers. The study findings reveal that stress and coping among caregivers could manage to prevent further complication. The study had concluded that the structured teaching programme on stress and coping effectively reduced the level of stress and enhanced level of coping of caregivers of hospitalized patient. $^{22}$

Nirmanmoh Bhatia et al (January 2011) carried out" a hospital based cross sectional study on occupational stress amongst nurses from two tertiary care hospitals in Delhi." Samples were 87 randomly selected staff nurses. Data was collected using self-administered questionnaire on stressors in daily life and at workstation and socio demographic profile. Results revealed $87.4 \%$ of nurses reported occupational stress. Highly stressful sources were Time Pressure, handling various issues simultaneously such as work situation and responsibilities. High level of skill requirement of the job was the most important stressor directly related to nursing profession. The study concluded as high prevalence of stress found amongst nurses and suggests that the need for stress reduction programmes targeting specific important stressors. ${ }^{23}$

Beverly J. Myers (2010) had presented " a mixed methods study on organizational support, perceived social support, to assess stress among psychiatric nurses at Albama." The role social support received at work, personal characteristics, and work factors play an important role in nurses' decisions to leave a current job position examined based on the survey data obtained from a convenience sample of 321 psychiatric nurses registered with the Alabama Board of Nursing. The significant predictors of psychiatric nurse's stress in the study perceived support from the health care organization, family social support, age, gender, nursing education, years of nursing experience, hours worked each week, and years in current job position. Psychiatric nurses appeared to be at a greater risk for stress if they perceive that the physical demands of the job exceed their abilities that the requirement of the job interferes with family obligations, level of education, lack appreciation and years of nursing experience. ${ }^{24}$

Hsu H. Y. et al (July 2010) conducted "a cross sectional study among nurses on job stress, achievement motivation and occupational burnout in Taiwan." Sample was selected 121 nurses through simple random sampling technique. The results indicate that overall job stress ranged from medium to high. The greatest source 
of job stress was organizational interaction followed by job load and role conflict. The study concluded that job stress is a predictor of occupational burnout may influence the quality of care by the nurses. ${ }^{25}$

Urmila Rani Srivastava (June 2010) done "an experimental study of Stress and negative mental health outcomes related to shift work at Varanasi, India." Data collected using a self-reported questionnaire including general health related questions and compared with control Group of day worker. Finding provide evidence that shift workers significantly experienced higher levels of job and life stress, the related stressors are role ambiguity, role conflict and work overload were the major predictors of negative mental health outcomes among shift workers. It adds that shift work is opposed to the human circadian system causes multiple physiological, psychological and psychosocial problems for shift workers. ${ }^{26}$

Eleni Moustaka (April 2010) investigated "a study to assess sources and effects of Work-related stress in nursing at Thrace, Europe." Method of this study using web sites for reviewing various publications and abstracts around the exact theme 'stress, occupational stress, and nursing'. It results that a number of aspects of working life are link with stress, namely work overload and role-based factors such as lack of power, role ambiguity, and role conflict. Threats to career development and achievement, including threat of redundancy, being undervalued and unclear promotion prospects are stressful. Stress is associated with reduced efficiency, decreased capacity to perform, a particular type of hospital unit, stress arises from the physical, psychological, and social aspects of the work environment. High levels of stress adversely affect patient care. ${ }^{27}$

Kane PP (April 2009) carried out “ an exploratory study to identify stress causing psychosomatic illness among nurses at 2 hospitals in Maharashtra." Demographic data collected by a questionnaire and stress assessed by modified stress assessment rating scale. Data collected from 106 staff nurses. The results showed that $26.42 \%$ had mild stress, $66.04 \%$ had moderate level of stress, and $7.55 \%$ had severe level of stress. The work related stress include not finishing work at time (78.3\%), backache due to standing for long hours $(61.3 \%)$, shortage of staff $(58.5 \%)$ and night duty $(20.8 \%)$. $^{28}$

Christopher Sudhaker (December 2009) reviewed "a study to assess job stress, coping strategies and the job quality index of nurses working in selected multispecialty hospitals at Mangalore." This study adopted survey approach and 60 staff nurses selected using non-probability convenience sampling technique. Survey approach adopted for data collection. Demographic Performa of nurses collected using Job Stress Index, Coping checklist, and Job quality index. The results of the study revealed that the nurses had moderate to high levels of stress. The occupational stress costs a de-motivated and underproductive workforce. The study shows that there is close relationship between coping strategies, job quality, and the job stress. Improving these variables will help to improve Job satisfaction thereby improves the quality of nursing care. ${ }^{29}$

Dr. M. I. Noor azlin (2006) conducted "a descriptive study aimed to Prevalence of Stress and Coping Mechanism among Staff Nurses in the Intensive Care Unit at Kebangsaan, Malaysia." The study samples were 67 staff nurses examined the relationship between working environment, socio-demographic data and factors influencing stress. Findings indicated that stress symptoms experienced by 100 per cent of staff nurses.Working experience, critically ill patients and environmental factors are contributing to the stress experienced by the nurses. ${ }^{30}$

Dr. Richard A. White (2006) had done "a Masters Theses and Doctoral Dissertations on Perceived stressors, coping strategies and stress pertaining to psychiatric nurse working on locked psychiatric units at Eastern Michigan." The theses say's experience in mental health nursing was the significant demographic characteristic with correlation to emotional exhaustion, concluded that psychiatric nurses with more experience demonstrated fewer stress while the nurses with less experience shows depersonalization and experiencing higher levels of stress. The study found relationship among perceived stressors, coping strategies, and stress. ${ }^{31}$

Atish Taukari and Tanmay Bhattacharya (2004) had done "a Comparative Study of Role Stress in Government and Private Hospital Nurses in Mumbai." This paper explores nurses' occupational stressors and coping mechanisms. Occupational stress among nurses appears to vary according to individual and job characteristics. Common occupational stressors among nurses are workload, role ambiguity, interpersonal relationships and death \& dying concerns. Emotional distress and psychological morbidity result from occupational stress. ${ }^{32}$

Purvi Parikh et al (2004) investigared “Occupational Stress and Coping among Nurses' at Powai, Bombay." Among nurses, occupational stress appears to vary according to individual perception, and job characteristics. Common occupational stressors among nurses are workload, role ambiguity, and interpersonal relationships. Emotional distress and psychological morbidity could also result from occupational stress. Nurses' common coping mechanisms include problem solving, social support, and avoidance. Coping and job satisfaction appear to be reciprocally related. Prophylactic and curative measures are important for nurses at both personal as well as organizational levels. ${ }^{33}$ 


\section{2 - Literature Review Related To The Effectiveness Of The Progressive Muscle Relaxation Therapy}

Rob ( 2013) reported in move 2 wellness that Progressive muscle relaxation involves a two-step process in which you systematically tense and relax different muscle groups in the body.With regular practice, progressive muscle relaxation gives you an intimate familiarity with what tension-as well as complete relaxation-feels like in different parts of the body. This awareness helps you spot and counteract the first signs of the muscular tension that accompanies stress. And as your body relaxes, so will your mind. You can combine deep breathing with progressive muscle relaxation for an additional level of stress relief. ${ }^{34}$

Nayak H K, Hemant Tiwari et al (2011) had carried out "a community-based cross-sectional study to assess the prevalence and pattern of stress relaxation practices in Ahmedabad city, Gujarat, India." The prevalence of different types of Stress Relaxation practices in relation with their socio demographic profile studied. Results reveals that out of 904 persons above 20 years of age were surveyed among them 310 doing Stress Relaxation practices were able to maintain balance between work and other activities than non - stress relaxation practices group. Also concluded that research study of the stress among the workers of sedentary occupation should be carried out. ${ }^{35}$

Liza varvogli , Christina darviri (2011) reported in "stress management techniques, evidence based procedures that reduce stress and promote health" for post graduate programme of stress management and health promotion, Athens medical school, university of Athens, stated that after a thorough literature review in major databases (MEDLINE, Scopus, Science Direct) the following techniques were identified and are presented and briefly discussed here Progressive muscle relaxation, Guided imagery, and emotional freedom technique. ${ }^{36}$

Gregory E. Harris (2010) reviewed "a progressive muscle relaxation technique is an effective treatment for numerous psychological and physical conditions when used in a thorough and systematic manner at University of Calgary." Progressive Muscle Relaxation Technique often overlooked by helping professionals. It is a viable treatment option. This article reviews research on the treatment efficacy of Progressive Muscles Relaxation Technique describes how to effective use it with clients. It is hope that helping professionals will come to understand the proper uses and potential benefits of Progressive Muscles Relaxation. ${ }^{37}$

Ghafari S. et al (August, 2009) had done "a quasi experimental research study on "Effectiveness of applying progressive muscle relaxation technique for quality of life of patients with multiple sclerosis at Fasa, Iran." Study concluded as Progressive Muscle Relaxation Technique is practically feasible and is associated with increase of life quality of multiple sclerosis patients; so that health professionals need to update their knowledge about Progressive Muscle Relaxation Technique as complementary therapies. ${ }^{38}$

Max G Feirstein (2009) a dissertation thesis of "a quasi experimental investigation, "Moderate effects of worry on group-induced relaxation states' in Australia." An experimental study was to determine whether the characteristics of absorption or worry would moderate by the effects of progressive muscle relaxation technique or guided imagery delivered to groups. Twenty male and 49 female students were administered either progressive muscle relaxation technique or imagery by a certified hypnotherapist. Although both treatments produced significant increases in relaxation and reductions in stress and anxiety, relaxation scores increasing from pre-test to post-test and stress and anxiety decreasing, It is suggested that progressive muscle relaxation technique may hold certain inherent benefits over imagery, as it may be less likely to were cause adverse effects. $^{39}$

Ohmori F. (2007) had tested "exercise-induced blood flow tested in relation to progressive muscle relaxation technique at New York." Different multi-component like cognitive, relaxation and exposure techniques for the treatment of generalized anxiety have shown significant improvements in blood circulation and reduction in anxiety. The study recommended Progressive Muscle Relaxation Technique is a self-control procedure as part of these treatments. It has proven to be effective in the treatment of anxiety. ${ }^{40}$

Giju Thomas (2006) carried out "A quasi experimental study to determine the effectiveness of progressive muscle relaxation technique on anxiety among elderly people in selected old age home at Bangalore." Study was carried out in sarvodaya old age home, bangalore. Data was obtained from the 40 elderly persons staying in sarvodaya old age home through the standard state trait anxiety inventory scale the level of anxiety was assessed. Purposive sampling technique was used . the finding of the study reveals that the mean level of anxiety during pretest was 89.82 and post test it was reduced to 69.55. there was an effectiveness found after STP of progressive muscle relaxation technique through statistical analysis by using paired ' $\mathrm{t}$ ' test. $(\mathrm{t}=$ $5.524 \mathrm{P}<0.05)^{41}$

Conrad A. \& Roth W. T. (2006) had conducted "a comparative study to find effectiveness of progressive muscle relaxation technique against the exercise in autogenic training as muscle relaxation therapy for anxiety disorders in USA." The exercises emphasize sensations involving the autonomic nervous system (e.g. warm hands, slow heart rate). Progressive Muscles Relaxation Technique has greater effects on muscles tension and symptoms associated with it than Autogenic Training does. Progressive Muscles Relaxation is more effective than Autogenic Training ${ }^{42}$. 
D Berry s. (1981) conducted a study on "An evaluation of progressive muscle relaxation on stress related symptoms in a geriatric population" Ten highly anxious women, between the ages of sixty-nine and eighty-four, participated in a five month study designed to test the hypothesis that progressive muscle relaxation would reduce psychosocial stress in a group of high risk senior citizens. The women, who had lost their husbands within the last five years, responded to an offer extended to nervous senior citizens to participate in a relaxation study. Five women were assigned to the treatment group and five to a control group. The treatment group received two weeks of baseline evaluation, ten weeks of one hour in vivo relaxation training, and ten weeks of home practice using taped instructions. The control group had an identical schedule except instead of progressive relaxation training they received a pseudorelaxation procedure and had no home practice. All participants were evaluated prior to training, at the end of training, and ten weeks after training. Participants were also measured on the following factors: 1) state and trait anxiety, 2) self-report muscle tension, 3) hours to fall asleep, 4) number of nocturnal awakenings, and 5) headaches. Results indicate significant differences on all five measures between the experimental and control group. With the exception of trait anxiety, the experimental group manifested significant improvements on the remaining five measures from baseline to end of training. For state anxiety, a significant improvement continued during the ten weeks of home practice following the end of training. ${ }^{43}$

Edmund Jacobson (1934) Progressive muscle relaxation technique is a relaxation technique of stress management developed by American physician. This progressive muscle relaxation technique is focus on tensing and releasing tensions in the 16 different muscle groups. Jacobson reasoned that since muscles tension usually followed as a byproduct of anxiety, one could lower and reduce anxiety by understanding and learning how to relax those muscles tension. ${ }^{44}$

\section{3 - Literature Review Related To Progressive Muscle Relaxation Therapy And Stress}

Minseon Park (April 2013) reviewed , "Evidence-based stress management: focusing on nonpharmacological procedure which reduce stress and promote health" Stress, which is defined as a situation in which the homeostasis of the physiological system of one's mind and body is threatened, is composed of two concepts: stressors and stress reactions. Meditation and progressive muscular relaxation are well-known and widely used procedures to reduce the stress response and to improve quality of life. ${ }^{45}$

National Center For Complementary And Alternative Medicine (NCCAM) (FEB 2013) reported that Relaxation techniques include a number of practices such as progressive muscle relaxation, guided imagery, biofeedback, self-hypnosis, and deep breathing exercises. Relaxation techniques (also called relaxation response techniques) may be used by some to release tension and to counteract the ill effects of stress. This fact sheet provides basic information about relaxation techniques, summarizes scientific research on effectiveness and safety, and suggests sources for additional information. ${ }^{46}$

Dolbier, christyln, rush, taylor e. ( Feb 2012), carried out "a study to examine the efficacy of abbreviated progressive muscle relaxation (APMR) to enhance physiological and psychological functioning among high-stress college students." Participants $(\mathrm{N}=128)$ with high Perceived Stress Scale scores. After random assignment, for $20 \mathrm{~min}, 66$ experimental group participants underwent APMR lying down and 62 control group participants lied down quietly. Pre- and post intervention measures included the Endler Multidimensional Anxiety Scale, relaxation items, electrocardiograph heart rate and heart rate variability (HRV), and salivary cortisol. Compared with the control group, the experimental group demonstrated significantly greater increases in mental (Cohen's $d=0.32$ ) and physical (Cohen's $d=0.32$ ) relaxation, and normalized high-frequency HRV (Cohen's $d=0.29$ ), and decreases in low- to high-frequency HRV ratio (Cohen's d = 0.31). Small effect sizes were observed for anxiety, normalized low-frequency HRV, and cortisol. Analyses of the reliability and clinical significance of these changes indicate trends in the expected direction. These findings indicate an APMR intervention can have significant short-term effects, both reducing detrimental and enhancing beneficial functioning in high-stress college students. ${ }^{47}$

Kathleen Romito, MD - family medicine, Lisa S. Weinstock, MD psychiatry (May , 2010) reported in WebMD Medical Reference From Health wise that When you have anxiety or stress in your life, one of the ways your body responds is with muscle tension. Progressive muscle relaxation is a method that helps relieve that tension. ${ }^{48}$

Mohsen yazdani (2010), investigated a study on "the effectiveness of stress management training programme (which included progressive muscle relaxation technique) on depression, anxiety and stress of the nurses" in Isfahan university of medical science with 68 samples by using randomazied quasi experimental trial, result saws that there was no significant difference before the intervention in depression, anxiety and stress mean score of two groups, after the intervention, the mean score of anxiety and stress in the intervention group was 5.09 (4.87) \& 8.93 (6.01) and in the control group was 10 (6.45) \& 13.17 (7.20). this reduction also had been remained after a month. ${ }^{49}$ 
Khanna A. paul M and sandhu JS , (2007), had done a study on, "efficacy of two relaxation techniques in reducing pulse rate among stressed females", at gurunankdev university, Punjab with 30 highly stressed female and randomly assigned to 3 groups $(\mathrm{N}=10$ each) (a) group 1 receiving gaalvanickin resistance feedback (b) group 2 receiving progressive muscle relaxation training (c) group3 control. Results indicated that progressive muscle relaxation training can significantly reduce high pulse rate as compared to other two group.CAT scores were reduced by $50.48 \%$ in Progressive Muscle Relaxation group after training. ${ }^{50}$

Maxwell V. Rainforth, Robert H. Schneider (2007) conducted a study on Stress Reduction Programs in Patients with Elevated Blood Pressure: A Systematic Review and Meta-analysis Substantial evidence indicates that psychosocial stress contributes to hypertension and cardiovascular disease (CVD). Seventeen trials with 23 treatment comparisons and 960 participants with elevated BP met criteria for well-designed randomized controlled trials and were replicated within intervention categories. Meta-analysis was used to calculate BP changes for biofeedback, $-0.8 /-2.0 \mathrm{~mm} \mathrm{Hg}(P=\mathrm{NS})$; relaxation-assisted biofeedback, $+4.3 /+2.4 \mathrm{~mm} \mathrm{Hg}(P=$ NS); progressive muscle relaxation, $-1.9 /-1.4 \mathrm{~mm} \mathrm{Hg}(P=\mathrm{NS})$; stress management training, $-2.3 /-1.3 \mathrm{~mm}(P$ $=\mathrm{NS})$; and the Transcendental Meditation program, $-5.0 /-2.8 \mathrm{~mm} \mathrm{Hg}(P=0.002 / 0.02) .{ }^{51}$

Melissa Stoppler, M.D (may 2005) reported in Medicine Net. Com that Progressive muscle relaxation (PMR) is a deep relaxation technique that has been effectively used to control stress and anxiety, relieve insomnia, and reduce symptoms of certain types of chronic pain. Progressive muscle relaxation is based upon the simple practice of tensing, or tightening, one muscle group at a time followed by a relaxation phase with release of the tension. Doctors have used progressive muscle relaxation in combination with standard therapies for symptom relief in a number of conditions, including headaches, cancer pain, high blood pressure, and digestive disturbances. ${ }^{52}$

Jeong, Is (2004) investigated study on, "effect of progressive muscle relaxation using biofeedback on perceived stress, stress response, climatric symptoms of middle aged women" at korea with 36 samples by using cross over pre-post test design result saws that progressive muscle relaxation technique was shown to be effective in reducing physiological stress responses. It was foundthat pulse rate decreased by $11.21 \%$ and electrodermal responsesincreased by $35.51 \%$ after 45 min of relaxation training. ${ }^{53}$

\section{Material And Method}

Research methodology indicates the general pattern of organizing the procedure for gathering valid and reliable data for an investigation. The content of this chapter includes research approach, description of setting and population, sampling technique, sample population, description of sample, tool selection, construction, description, and rationale of the tool, procedure of data collection, data analysis, and statistical methods used.

\subsection{Research Approach}

The selected research approach for this study is Quantative approach used in the present study to assess the effectiveness of the Progressive Muscles Relaxation Therapy on stress among staff nurses working in selected Hospitals at vadodara city.

\subsection{Research Design}

The research design selected for the present study was pre experimental one group pre-test post-test design. The Investigator had developed Stress Assessment Rating Scale for evaluation of pretest and post test stress score of the samples. For manipulation of independent variable Investigator had prepared a plan for demonstration on the Progressive Muscles Relaxation Technique and observes its effect on the stress of samples as dependent variable. The research design adopted for the study is diagrammed as:

Pre-test Intervention Post-test

$\begin{array}{llll}\text { One group } & \mathrm{O} 1 & \mathrm{X} & \mathrm{O} 2\end{array}$

KEY -:

$\mathrm{O} 1=\mathrm{It}$ is the First Observation means assessment of pre-test score of level of stress among staff nurses working in selected hospitals at vadodara city.

$\mathrm{X}=$ Treatment to the group is the administration of the Progressive Muscles Relaxation therapy.

$\mathrm{O} 2=\mathrm{It}$ is the second observation means assessment of post-test score of level of stress among staff nurses working in selected hospitals at vadodara city.

Rationale

This design helped the investigator to manipulate the independent variables, demonstration cum lecture on the Progressive Muscles Relaxation Therapy and to observe its effect on the dependent variable, stress among staff nurses. In one group pre test post test design, the dependent variable was measured before application of the independent variable after an appropriate period of time has elapsed and then the dependent variable was measured again. In the analysis of the data the difference between the initial and terminal measurements represents the effect of the independent variable. 


\subsection{Research Variables:}

Independent Variable

Progressive Muscles Relaxation Therapy

Dependent Variable

Stress among the staff nurses working in the selected hospitals at vadodara city.

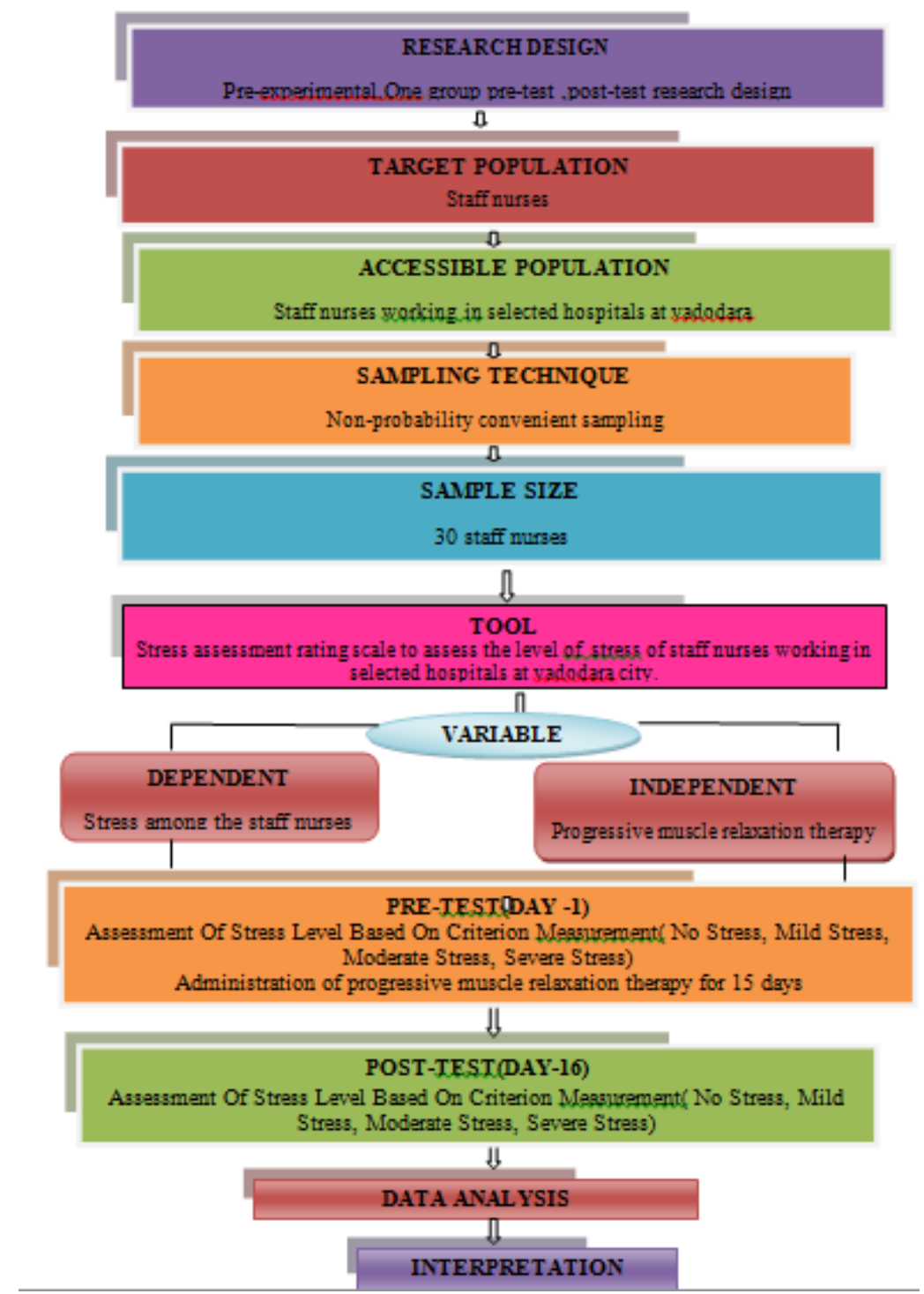

\subsection{Research Setting}

Research setting is physical location and condition in which data collection takes place in a study. Investigator conducted study in the selected Hospitals at vadodara city.

Rationale

The hospitals provide preventive, promotive, curative, and rehabilitative services for health. It also has facilities of education and research. The criteria and rationale for selecting these hospitals was that the availability of subjects, easy access, and feasibility of conducting study.

\subsection{Target Population}

Target population refers to the population that investigator wishes to study the population about which to generalize. In this study, the target population consisted of Staff Nurses working in the selected hospitals at vadodara city.

\subsection{Sample Size And Sampling Technique}

Sample is a portion of population selected for observation and analysis. 
The samples of the study will be selected by using non probability convenient sampling technique according to inclusive criteria as availability of samples.

In the study the sample size consitutes of 30 staff nurses from selected hospitals of vadodara city.

\section{7criteria For Sample Selection:}

The inclusion as well as exclusion criteria used for the present study is as follow:

\section{Inclusion Criteria}

$>\quad$ Staff nurses that are qualified and registered

$>\quad$ Staff nurses who are willing to participate in the study.

$>\quad$ Staff nurses who can read, write and understand English language.

\section{Exclusion Criteria}

$>\quad$ Staff nurse who do not want to participate and practice progressive muscle relaxation therapy

Staff nurses who are having problems regarding pulled muscles, broken bones, or any medical contraindication for physical activities.

$>\quad$ Staff nurses who receives any other alternative therapy.

$>\quad$ Staff nurses who have no stress in the result of pre test.

\subsection{Selection And Development Of The Tool For Data Collection}

The investigator has selected the following tool for data collection according to the objectives of the study.

Demographic data collection tool and Stress assessment rating scale used in the present study to assess the stress of the staff nurses working in selected Hospitals at vadodara city.

Tool is divided into two sections as follows:

Section - I - Demographic Data Collection Tool.

Section -II- Stress Assessment Rating Scale.

Rationale:

1. It is relatively in expensive to employ.

2. The instrument is quite simple to develop.

3. The Stress assessment rating scale is self-reporting type that can provide chance to respondent to report his/her own experience of stress without any inhibition of investigator.

4. It is easy to administer to the large group

5. Written record that eliminating bias and variety of information

\section{The Development Of Tool}

The development of tool was a systematic procedure in order to make the tool more practical oriented. The investigator reviewed the literature of various study on various stress scales made for assessing stress. Investigator reviewed books, articles, website, published and unpublished thesis to develop the tool to assess stress among staff nurses.

\section{Section - I - The Demographic Data Collection Tool.}

The investigator developed this tool as per the objectives of this study, six demographic variables selected for association with pretest stress score. That are age, sex, marital status, monthly family income, working area and total work experience.

\section{Section-II- Stress Assessment Rating Scale.}

The investigator prepared this tool based on the objective of the study to assess the stress experienced by staff nurses working in the selected Hospitals at vadodara city .

1. This Scale consist 30 statements to measure the level of stress experienced by sample in their daily professional life. Total 30 statements comprising various vulnerable area of the nursing care like job design and workload, patient care, peer problems, problems related to supervisor/ physician, uncertainity concerning treatment and miscellaneous.

2. The samples have to state how far it is true in his or her case feel stressed. This tool is a five-point rating scale with responses Samples have to select one of the suitable answer as

Almost never - 0,

Rarely -1,

Sometimes-2, 
Often-3,

Almost always-4

in their case and put a tick mark $(\sqrt{ })$ in given space $(\square)$ in front of each statement in the scale. Samples have to give answers of all statements.

3. All questions are positive. There is no negative question in this tool.

4. Thus, the total score will be count for each sample. Finally, the level of score will be assessed as per the following criteria. The stress of sample will be graded into

No $\operatorname{Stress}(00-30)$

Mild Stress $(31-60)$

Moderate Stress $(61-90)$

Severe Stress (091-120)

Blue print on number of items for source of stress assessing score of stress among the staff nurses on Stress assessment rating scale

Table 1: Blue Print For Source Of Stress On Stress Assessment Rating Scale

\begin{tabular}{|c|c|c|c|c|}
\hline Sr No. & Source Of Stress & $\begin{array}{c}\text { Total Number } \\
\text { Of Items }\end{array}$ & Minimum Score & Maximum Score \\
\hline 01 & Job Design And Workload & 05 & 00 & 20 \\
\hline 02 & Patient Care & 05 & 00 & 20 \\
\hline 03 & Peer Problems & 05 & 00 & 20 \\
\hline 04 & Problems Related To Supervisor/Physician & 05 & 00 & 20 \\
\hline 05 & Uncertainity Concerning Treatment & 05 & 00 & 20 \\
\hline 06 & Miscellaneous & 05 & 00 & 20 \\
\hline & Total & 30 & 00 & 120 \\
\hline
\end{tabular}

\subsection{Validity Of The Tools}

Validity refers to getting results that accurately reflect the concept being measured. A valid measure refers to the degree to which an instrument measures what it is supposed to be measuring. In practice, validity can also refer to the success of the research in retrieving "valid" results.

Content validity refers to the degree to which the test actually measures or is specifically related to the traits for which it was designed. (Polit, 1999). Identifying the universe of content is not an easy task. It is, therefore, usually suggested that a panel of experts in the field to be studied be used to identify a content area.

To ensure content validity of the tool, the self structured questionnaire was send to 10 experts. The experts were selected based on their clinical expertise, experience and interest in the problem being studied. They were requested to give their opinions on the appropriateness and relevance of the items in the tool. Modifications of items in terms of simplicity and order were made.

On common agreement a few additions and deletions were made in the tool and content. As a whole the suggestions and comments of experts included grammatical corrections of sentences. Else the tool was found to be relevant.

The necessary modification has been done as per the expert's advice. The recommendations and suggestions of the experts were considered to modify the items of tool as well the content of structured teaching programme.

\subsection{Reliability}

The reliability of measuring instruments a major criterion for assessing its quality and accuracy. Reliability of an instrument is the degree of consistency with which it measures the attributes it is supposed to be measured.

In order to establish the reliability of the tool it was administered to five staff nurses. To establish the reliability of the stress assessment rating scale, split half method was used, Spearman-Brown's Prophecy formula was used for correlation coefficient, which was found to be 0.9 that is more than 0.7 so it considers as strongly reliable. Hence, the Stress assessment rating scale was found reliable tool for data collection. Thus, the Stress assessment rating scale finalized for data collection of the study.

\subsection{Pilot Study}

Pilot study is a small-scale version or trial run, done in preparation of the main study.

The main objective of the pilot study was to help the researchers to become familiar with the use of tool and find out the difficulties to conduct the main study. The pilot study was conducted from $20^{\text {th }}$ October 2013 to $28^{\text {th }}$ October 2013. The purpose of the study was explained to the sample and confidentiality was assured. Consent was obtained from sample. On the first day tool was administered to five staff nurse who fulfilled the criteria for selection of the study. 
The progressive muscle relaxation therapy was taught on the same day of pre-test till seven days. On the eighthday, the post-test was conducted with the same tool to assess the reduction in stress level score.

The data collected was analyzed using descriptive and inferential statistcs.

The significance of difference in the pre-test and post-test was found using paired ' $t$ 'test. The study was found feasible and practicable.

\subsection{Plan For Data Collection}

Formal permission was taken from concerned authorities and permission was obtained from the selected hospitals. Thirty samples were selected by randomization. Purpose of the study was explained and consent was obtain from samples. Data was collected using tool. Demographic data collection tool was used to know the demographic data of each sample. The pre test stress of the participant was assessed by Stress assessment rating scale. The demonstration and self-practice of Progressive Muscles Relaxation Therapy was used as intervention to relieve stress among staff nurses working in the selected Hospitals at vadodara city. The administration of progressive muscles relaxation therapy was applied on each sample, ones daily, for 15 days then post test was conducted.

\subsection{Plan For Data Analysis}

The data obtained were analyzed in terms of objectives of the study using descriptive and inferential statistics. The plan of data analysis was as follows:-

$>\quad$ Organize data in master sheet or computer.

$>\quad$ Personal data was analyzed in terms of frequencies and percentages.

$>\quad$ The level of the stress before and after administering progressive muscle relaxation therapy was analyzed in terms of frequencies, percentages, mean, median, standard deviation.

$>\quad$ The significance of the difference between pre- test and post - test stress score was determined by paired " $t$ " - test.

$>\quad$ The association between level of stress and demographic variables was determined by ANOVA.

$>\quad$ Data is presented in the form of tables and graphs.

\section{Summary}

D This chapter dealt with research methodology, i.e., research approach, research design, setting, sample, population, reliability, pilot study, method of data collection and plan for data analysis.

D A study was carried out on 30 staff nurses working in selected hospitals at vadodara city to assess the effectiveness of progressive muscle relaxation therapy on stress of staff nurses. Stress assessment rating scale was prepared and validity and reliability of the tool was tested. Data was collected after obtaining permission from the concerned authority to conduct pre-test, administer progressive muscle relaxation therapy. Data was analyzed by using descriptive and inferential statistics presented in the form of tables, graphs and figures.

\section{Results}

Kerlinger (1973) defined analysis as the "categories, ordering, manipulating, summarizing of data to obtain answer to research questions. "The purpose of analysis is to reduce data to an intelligible and interpretable form so that the relation of research problem can be studied and tested.

The main purpose of this chapter is to organize and summarize the data for easy interpretation. This chapter deals with the analysis and interpretation of data. The data collected from 30 samples to assess the stress level and to determine the effectiveness of "Progressive Muscle Relaxation Therapy" among staff nurses working in selected hospitals at Vadodara city"

During the analysis the data were reduced to interpretable form to summarize the findings. The collected data tabulated on the master sheet and analyzed using descriptive and inferential statistics.

The research process and proposed methodology guided the researcher in the selection of the appropriate data analysis technique. The data collected was analyzed on the basis of objectives of the study. The Objectives Of The Study were:vadodara city.

$>\quad$ To determine the effectiveness of the Progressive Muscles Relaxation Therapy on level of stress among staff nurses working in the selected Hospitals at vadodara city.

Hypothesis

To find out the association between the post test stress score with selected demographic variables.

$\mathrm{H} 1$ - there will be significant difference in the level of stress before and after administering Progressive Muscle Relaxation Therapy among staff nurses working in selected hospitals at vadodara city. 
$\mathrm{H} 2$ - there will be significant association between level of post test stress of staff nurses with the selected demographic variables.

\section{Analysis And Interpretation Of The Data}

Major findings of the study presented under following headings:

4.1 Section I: - Deals with the analysis and Interpretation of selected demographic variables of the samples such as Age, Sex, Marital Status, Monthly Family Income, Working Area and Total Working Experience in terms of frequency and percentage.

4.2 Section II: - Deals with the analysis and Interpretation of the stress level of the sample Collected on stress assessment rating scale before and after administration of Progressive Muscle Relaxation Therapy.

4.3 Section III: - Deals to evaluate the effectiveness of the Progressive Muscle Relaxation Therapy.

4.4 Section IV: - Deals to find an association between post test stress scores of the nurses with selected demographic variables.

\subsection{Section I}

Frequency And Percentage Distrubition Of Demographic Variables

This section deals with the analysis of the demographic variable according to their age, sex, marital status, monthly family income, working area and total work experience.

The description of demographic variable of sample has been presented in the form of frequency and percentage and interpreted with the diagrams.

Table 2 : Frequency And Percentage Distribution Of Samples According To Their Demographic

\begin{tabular}{|c|c|c|c|c|}
\hline & Variables. & & \multicolumn{2}{|c|}{$\mathbf{N}=\mathbf{3 0}$} \\
\hline $\begin{array}{r}\mathrm{Sr} \\
\text { no. }\end{array}$ & Demographic Variables & Categories & Frequency & Percentage \\
\hline 1 & Age (in years) & $\begin{array}{l}20-29 \\
30-39 \\
40-49 \\
50-\text { above }\end{array}$ & $\begin{array}{c}12 \\
8 \\
5 \\
5\end{array}$ & $\begin{array}{l}40.0 \\
26.7 \\
16.7 \\
16.7\end{array}$ \\
\hline 2 & Sex & $\begin{array}{l}\text { Male } \\
\text { Female }\end{array}$ & $\begin{array}{c}7 \\
23\end{array}$ & $\begin{array}{l}23.3 \\
76.7\end{array}$ \\
\hline 3 & Marital status & $\begin{array}{l}\text { Married } \\
\text { Unmarried } \\
\text { Widow/widower } \\
\text { Live in relationship }\end{array}$ & $\begin{array}{c}19 \\
9 \\
1 \\
1\end{array}$ & $\begin{array}{c}63.3 \\
30.0 \\
3.3 \\
3.3 \\
\end{array}$ \\
\hline 4 & Monthly family income & $\begin{array}{l}\text { Below }-5000 \\
5001-10000 \\
10001-15000 \\
15001 \text { and above }\end{array}$ & $\begin{array}{c}1 \\
8 \\
10 \\
11\end{array}$ & $\begin{array}{c}3.3 \\
26.7 \\
33.3 \\
36.7 \\
\end{array}$ \\
\hline 5 & Working area & $\begin{array}{l}\text { ICU } \\
\text { Ward } \\
\text { Casualty } \\
\text { O.T. } \\
\end{array}$ & $\begin{array}{l}10 \\
15 \\
2 \\
3 \\
\end{array}$ & $\begin{array}{c}33.3 \\
50.0 \\
6.7 \\
10.0 \\
\end{array}$ \\
\hline 6 & Total work experience & $\begin{array}{l}5 \text { years and below } \\
6-10 \text { years } \\
11-15 \text { years } \\
16 \text { years and above }\end{array}$ & $\begin{array}{c}11 \\
5 \\
4 \\
10\end{array}$ & $\begin{array}{l}36.7 \\
16.7 \\
13.3 \\
33.3 \\
\end{array}$ \\
\hline
\end{tabular}

Data In Table - 2 Shows The Frequency And Percentage Distribution Of Samples Based On Demographic Variables:-

$>\quad$ Regarding Age categories of the respondents have been divided into four different categories. Among all, $40 \%$ respondents belong to age category of $20-29$ years of age which is the youngest category. $26.7 \%$ respondents belong to the age group of $30-39$ years, while $16.7 \%$ from each of the age group of $40-49$ and 50 - above. Table reveals that among the sample of the study majority of them belongs to the younger age group. (figure no : 3 )

Regarding Sex of the respondents have been depicted, which shows that majority of the respondents are female i.e. $76.7 \%$ of the total sample size, while the representation of male are only $23.3 \%$ in this particular study.

( figure no. 4 ) 
$>\quad$ Regarding Marital Status of the respondents has been divided into four different categories. Among all, $63.3 \%$ respondents are married. $30.0 \%$ respondents are unmarried, while $3.3 \%$ are widow/ widower. and $3.3 \%$ possessing live in relationship.( figure no. 5 )

Regarding Monthly Family Income (in INR ) of the respondents have been depicted, which shows that majority of the respondents are having 15001 and above monthly family income i.e. $11 \%$ of the total sample size, while the $10 \%$ of the samples are having monthly family income 10001-15000 . the respondents having monthly family income 5001-10000 are $8 \%$ and only $1 \%$ of the total sample is having monthly family income below 5000.

( figure no. 6 )

$>\quad$ Regarding Working Area of the respondents has been divided into four different categories. Among that, $33.3 \%$ respondents working in ICU. Majority of the respondents $50 \%$ are working in ward. while $6.7 \%$ are working in casualty and $10 \%$ of the respondents are working in O.T.

( figure no. 7 )

Regarding Total Work Experience ( year ) has been divided into four different categories. Among all majority of the sample are having work experience 5 years and below are $36.7 \%$ while $16.7 \%$ of samples are having work experience $6-10$ years. $13.3 \%$ of the samples are having $11-15$ years of work experience and 33.3 $\%$ of the samples are having 16 years and above work experience. ( figure no. 8 )
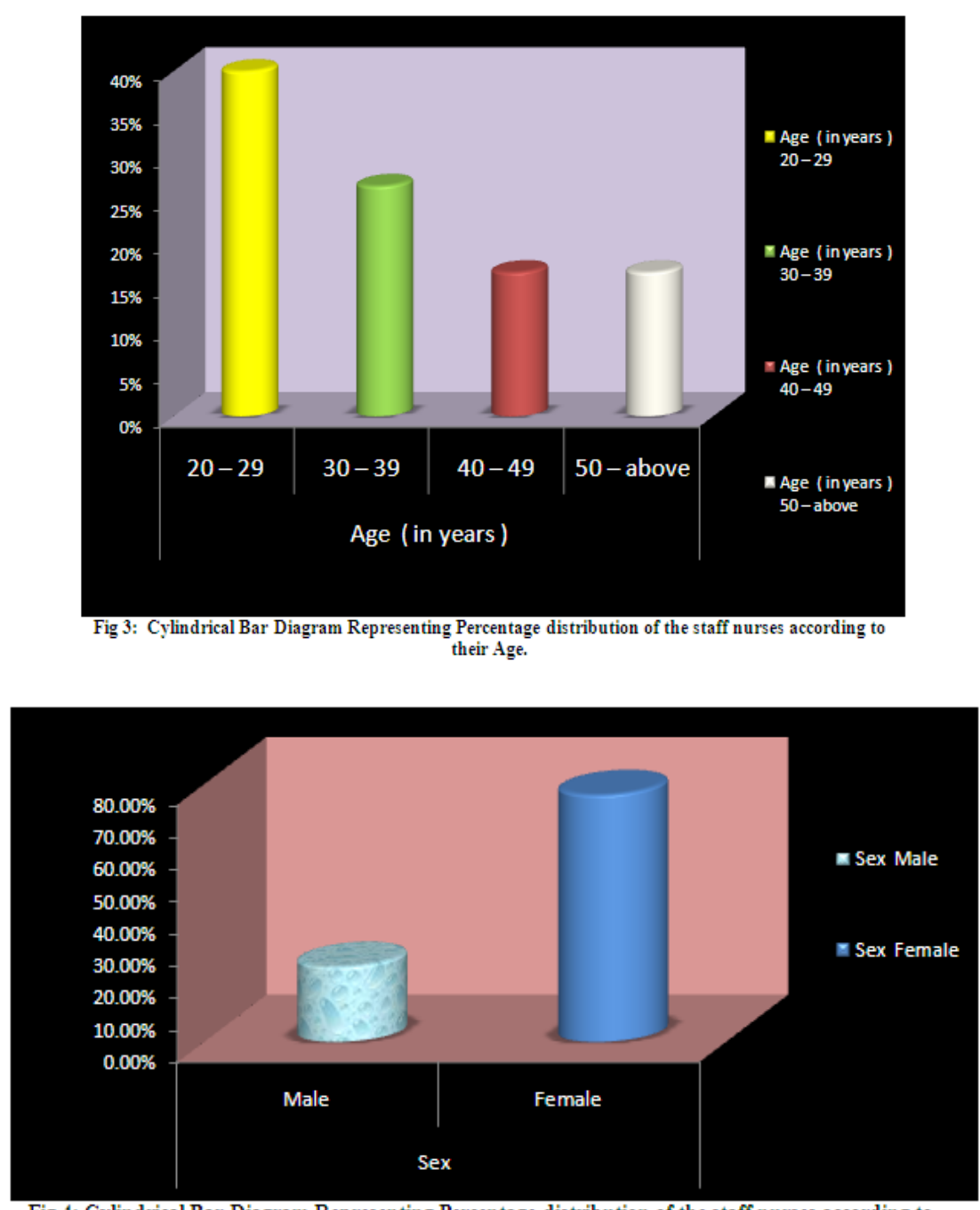

Fig 4: Cylindrical Bar Diagram Representing Percentage distribution of the staff nurses according to their Sex. 


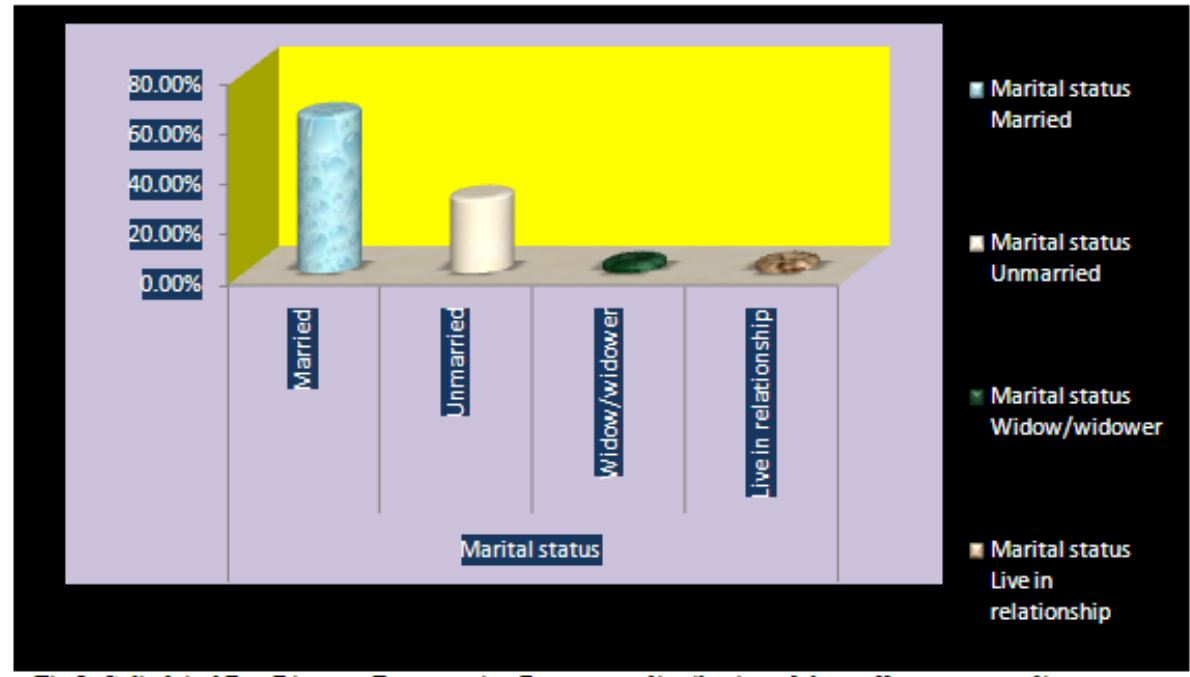

Fig 5: Cylindrical Bar Diagram Representing Percentage distribution of the staff nurses according to their Marital Status.

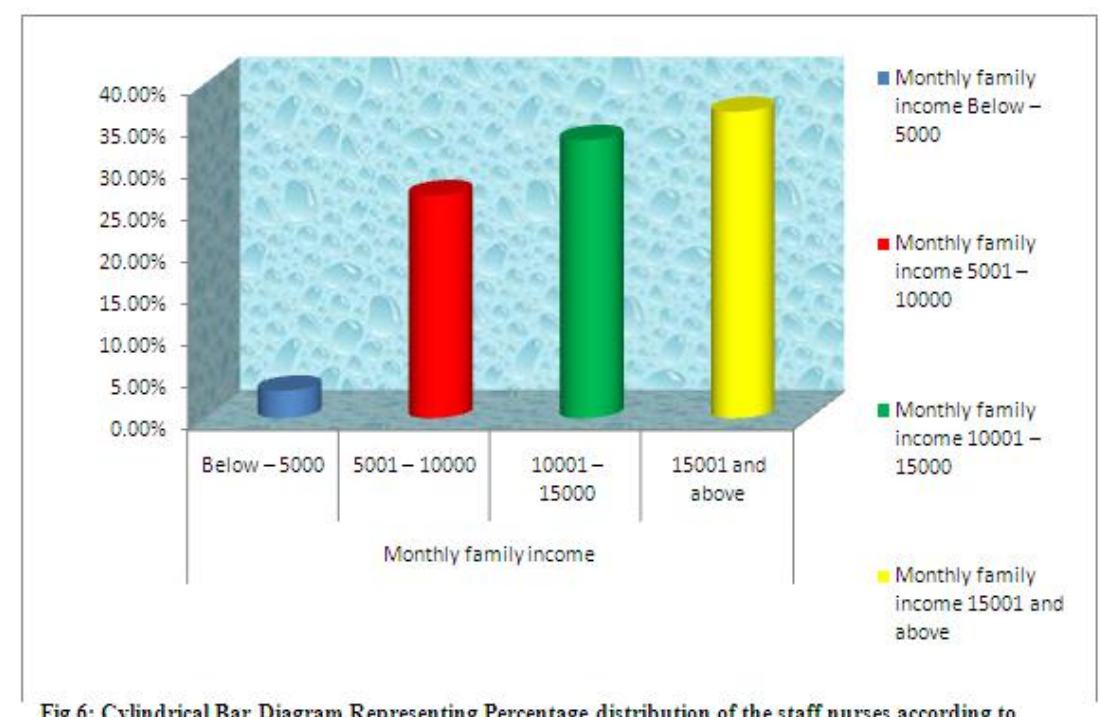

Fig 6: Cylindrical Bar Diagram Representing Percentage distribution of the staff nurses according to their Monthly Family Income (INR).

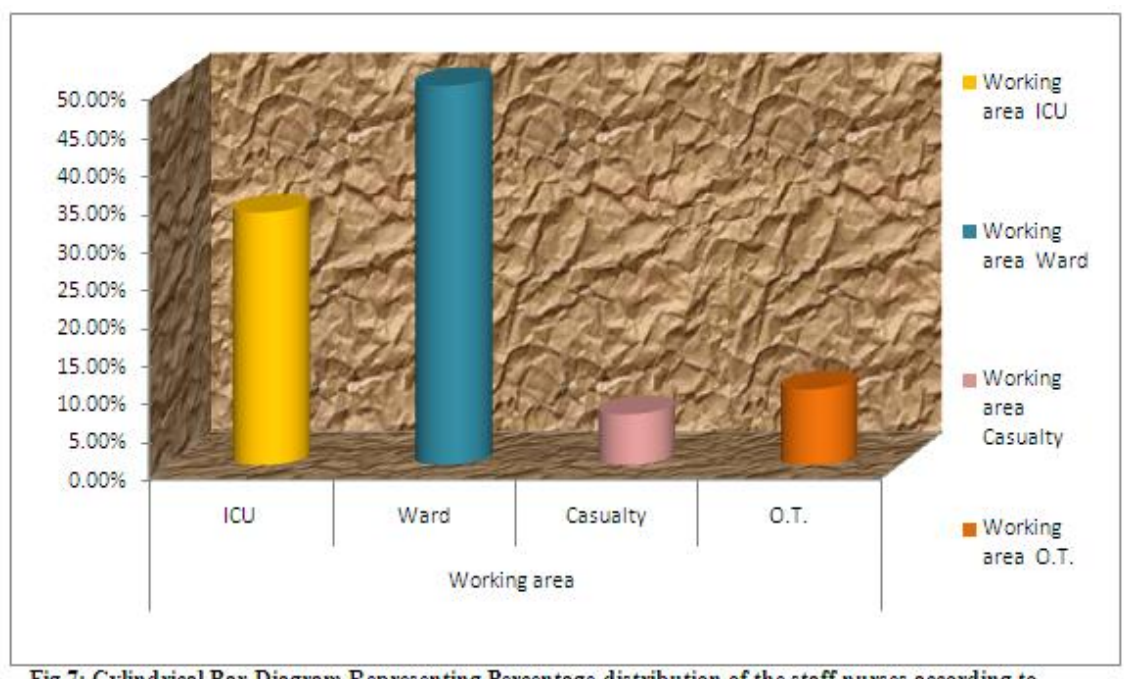

Fig 7: Cylindrical Bar Diagram Representing Percentage distribution of the staff nurses according to their Working Area. 


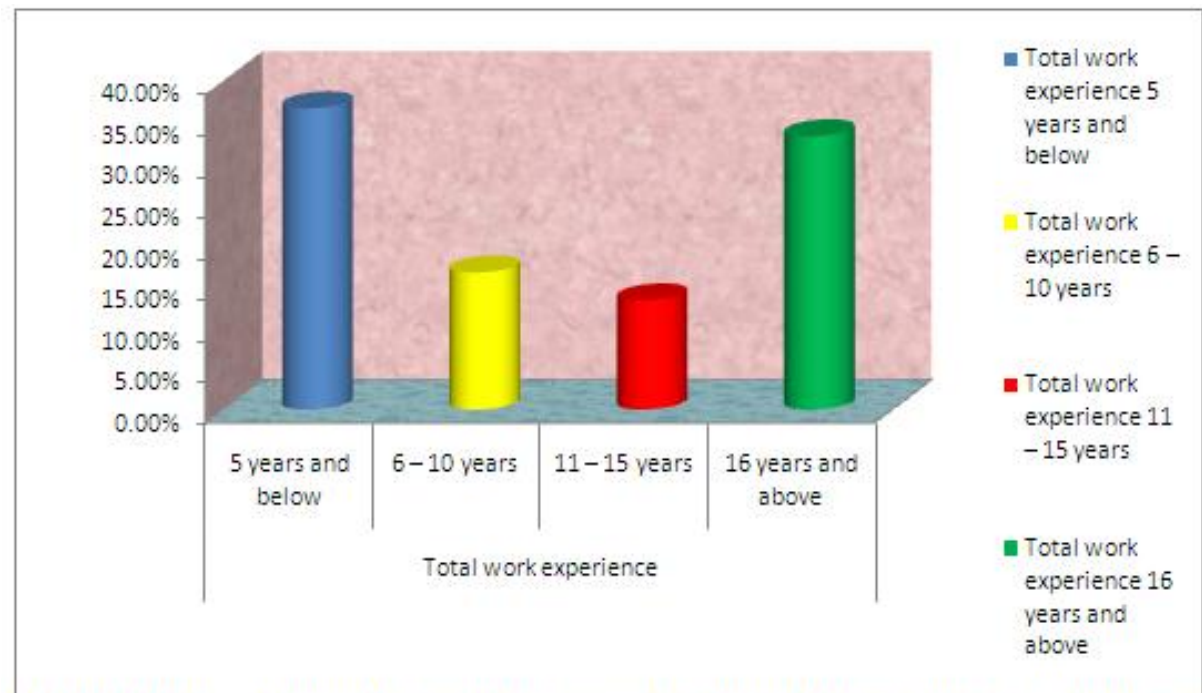

Fig8: Cylindrical Bar Diagram Representing Percentage distribution of the staff nurses according to their Total Work Experience.

\subsection{Section II}

Analysis And Interpretation Of The Stress Level Of The Sample Collected On Stress assessment rating scale Before And After Administration Of Progressive Muscle Relaxation Therapy.

Table 3: level of stress among staff nurses showing frequency and percentage of stress on stress assessment rating scale ( Pre Test )

( Objective 1: To assess the pre- test and post-test level of stress among staff nurses working in selected hospitals at vadodara city.)

\begin{tabular}{|c|l|c|c|}
\hline Sr no. & \multicolumn{1}{|c|}{ Stress level } & Frequency & Percentage \\
\hline 1 & No stress & 00 & - \\
\hline 2 & Mild stress & 14 & 46.67 \\
\hline 3 & Moderate stress & 12 & 40 \\
\hline 4 & Severe stress & 04 & 13.33 \\
\hline
\end{tabular}

Above table 3 reveals, that during pre tests zero (00\%) samples showing no stress, fourteen (46.67\%) samples showing mild stress and twelve (40\%) samples showing moderate stress and four ( $13.33 \%)$ samples having severe stress.

Table 4: level of stress among staff nurses showing frequency and percentage of stress on stress assessment rating scale ( Post Test )

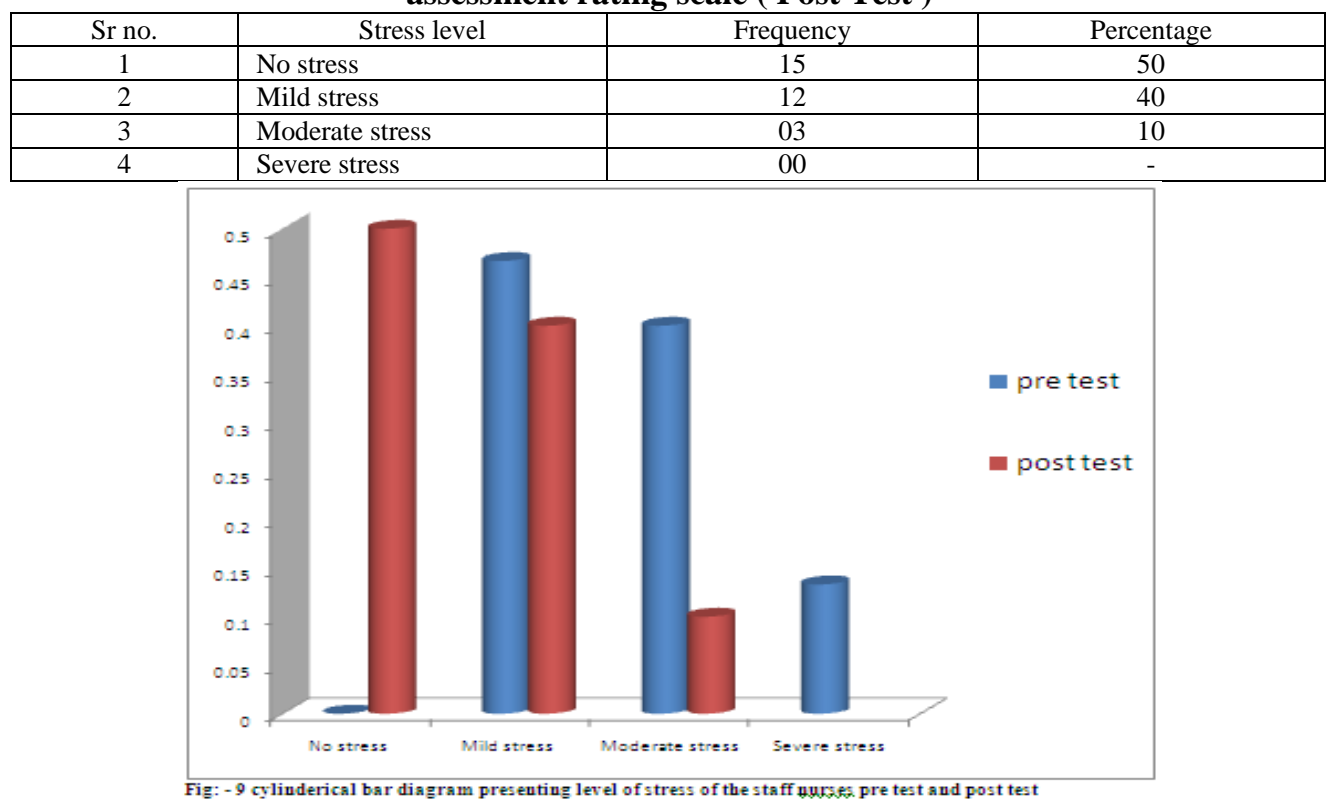


Table 4 shows that the fifteen $(50 \%)$ samples were showing no stress and twelve $(40 \%)$ samples showing mild stress and three ( $10 \%$ ) samples showing moderate stress. there is no samples having severe level of stress.

\subsection{Section III}

Evaluate The Effectiveness Of The Progressive Muscle Relaxation Therapy

In this effectiveness of Progressive Muscle Relaxation Therapy has been analyzed. Differential score between pre and post study have been calculated to check the impact of the progressive muscle relaxation therapy on stress among staff nurses working in selected hospitals at vadodara city.

(Objective 2 :- To evaluate the effectiveness of progressive muscle relaxation therapy on level of stress among staff nurses working in selected hospitals at vadodara city.)

Testing The Research Hypothesis $\mathrm{H}_{1}$

In order to determine the effectiveness of progressive muscle relaxation therapy on staff nurses hypothesis was formulated.

H1 - there will be significant difference in the level of stress before and after administering Progressive Muscle Relaxation Therapy among staff nurses working in selected hospitals at vadodara city.

Table 5 :- Testing The Hypothesis Effectiveness Of Progressive Muscle Relaxation Therapy

\begin{tabular}{|c|c|c|c|c|c|c|c|c|c|}
\hline \multirow{2}{*}{ Stress Variables } & \multicolumn{3}{|c|}{ Pre Test } & \multicolumn{3}{|c|}{ Post Test } & \multirow{2}{*}{$\mathrm{t}$ value } & \multirow{2}{*}{$P$ value } & \multirow{2}{*}{$\begin{array}{c}\text { Level of } \\
\text { significant } \\
0.05 \%\end{array}$} \\
\hline & Mean & $\mathrm{N}$ & Std. Deviation & Mean & $\mathrm{N}$ & Std. Deviation & & & \\
\hline $\begin{array}{c}\text { Job Design and work } \\
\text { load }\end{array}$ & 2.53 & 30 & 0.681 & 1.47 & 30 & 0.629 & 11.217 & .000 & $\mathrm{~S}$ \\
\hline Patient Care & 1.93 & 30 & 0.521 & 0.93 & 30 & 0.521 & 10.428 & .000 & $\mathrm{~S}$ \\
\hline Peer Problems & 2.23 & 30 & 0.568 & 1.2 & 30 & 0.407 & 13.676 & .000 & $\mathrm{~S}$ \\
\hline $\begin{array}{c}\text { Problem Related to } \\
\text { Supervisor }\end{array}$ & 2.13 & 30 & 0.819 & 1.27 & 30 & 0.64 & 7.549 & .000 & $\mathrm{~S}$ \\
\hline $\begin{array}{c}\text { Uncertainty } \\
\text { concerning treatment }\end{array}$ & 1.7 & 30 & 0.596 & 1.1 & 30 & 0.305 & 6.595 & .000 & $\mathrm{~S}$ \\
\hline Miscellaneous & 2.17 & 30 & 0.592 & 1.3 & 30 & 0.466 & 9.355 & .000 & $\mathrm{~S}$ \\
\hline Over All Score & 2.13 & 30 & .412 & 1.22 & 30 & .382 & 21.177 & .000 & $\mathrm{~S}$ \\
\hline
\end{tabular}

$\mathrm{t}(29,0.050)=1.699$

Above table 5 shows the area wise comparison of stress scores of staff nurses regarding job design and work load, patient care, peer problems, problems related to supervisor/ physician, uncertainity concerning treatment, miscellaneous value are compared and paired ' $t$ " test is applied at 0.05 level of significance. The tabulated " $\mathrm{t}$ " value for 29 degree of freedom is 1.699 and calculated value greater than in area wise distribution of stress score.

The calculated value were much higher than tabulated value at 0.05 level of significance which was statistically acceptable level of significance. So there is significance difference in stress score of nurses.

Table 6:- Significance Of Difference Between Over All Stress Scores Of Nurses

\begin{tabular}{|c|c|c|c|c|c|c|}
\hline $\begin{array}{c}\text { Over all stress } \\
\text { level }\end{array}$ & Maximum Score & Mean & Std. Deviation & Mean percentage & T -value & P value \\
\hline PRE TEST & 120 & 64.17 & 12.396 & 53.475 & 220.580 & \multirow{2}{*}{0.000} \\
\hline POST TEST & 120 & 36.67 & 11.460 & 30.55 & 200 \\
\hline
\end{tabular}

Above table 6 shows that statistically there was significant difference in stress score of the nurses working in selected hospitals at vadodara city. The calculated ' $t$ ' value 20.58 was much higher then the tabulated 't ' value 1.69 at $0.05 \%$ level of significance.

Also the calculated ' $\mathrm{p}$ ' is $>0.000$ which is ideal for any distribution and compared as acceptable 0.05 . so statistically prove that there was significant difference in stress score of the staff nurses after administering the progressive muscle relaxation therapy.

Hypothesis was tested by using paired " $t$ " test. The value of " $t$ " was calculated to analyze the difference in stress level of the staff nurses with their pre-test and post-test scores. The research hypothesis $\mathrm{H}_{1}$ was formulated to evaluate the effectiveness of progressive muscle relaxation therapy on stress among staff nurses working in selected hospitals at vadodara city. $\mathrm{H}_{1:-}$ ACCEPTED

$$
\text { 4.4 Section IV }
$$

To Find An Association Between Post Test Stress Scores Of The staff Nurses With Selected Demographic Variables. 
(Objective 3 :- To find out the association between post test stress score and selected demographic variables.) $\mathrm{N}=30, \mathrm{df}=29, \mathrm{t}(29,0.050)=1.699$

Table : - 7 association between post test stress score and demographic variables.

\begin{tabular}{|c|c|c|c|c|c|c|c|}
\hline \multicolumn{2}{|c|}{ Demographic Variables } & Mean & $\begin{array}{c}\text { Std, } \\
\text { Deviation }\end{array}$ & $\mathrm{N}$ & $\mathrm{t}$ value & $\mathrm{P}$ value & Significant \\
\hline \multirow{4}{*}{ Age in year } & $20-29$ & 36.25 & 9.392 & 12 & \multirow{4}{*}{.938} & \multirow{4}{*}{.437} & \multirow{4}{*}{ NS } \\
\hline & $30-39$ & 40.25 & 13.199 & 8 & & & \\
\hline & $40-49$ & 39.20 & 17.297 & 5 & & & \\
\hline & 50 and above & 29.80 & 3.768 & 5 & & & \\
\hline \multirow{2}{*}{ Sex } & Male & 34.29 & 4.821 & 7 & \multirow{2}{*}{.407} & \multirow{2}{*}{.529} & \multirow{2}{*}{ NS } \\
\hline & Female & 37.48 & 12.831 & 23 & & & \\
\hline \multirow{4}{*}{$\begin{array}{l}\text { Marital } \\
\text { status }\end{array}$} & Married & 37.21 & 12.488 & 19 & \multirow{4}{*}{264} & \multirow{4}{*}{.851} & \multirow{4}{*}{ NS } \\
\hline & Unmarried & 35.67 & 10.583 & 9 & & & \\
\hline & Widow/ widower & 30.00 & .000 & 1 & & & \\
\hline & Live in relationship & 44.00 & .000 & 1 & & & \\
\hline \multirow{4}{*}{$\begin{array}{c}\text { Monthly } \\
\text { family } \\
\text { income (INR } \\
\text { ) }\end{array}$} & Up to $5000 \mathrm{Rs}$ & 66.00 & .000 & 1 & \multirow{4}{*}{2.998} & \multirow{4}{*}{.049} & \multirow{4}{*}{$\mathrm{S}$} \\
\hline & 5001-1000 Rs & 36.63 & 11.904 & 8 & & & \\
\hline & $10001-15000 \mathrm{Rs}$ & 37.50 & 8.383 & 10 & & & \\
\hline & 15001 and above & 33.45 & 11.003 & 11 & & & \\
\hline \multirow{4}{*}{$\begin{array}{c}\text { Working } \\
\text { area }\end{array}$} & ICU & 32.90 & 6.100 & 10 & \multirow{4}{*}{.708} & \multirow{4}{*}{.556} & \multirow{4}{*}{ NS } \\
\hline & Ward & 39.53 & 14.735 & 15 & & & \\
\hline & Casualty & 38.50 & 6.364 & 2 & & & \\
\hline & O.T. & 34.33 & 7.506 & 3 & & & \\
\hline \multirow{4}{*}{$\begin{array}{l}\text { Total work } \\
\text { experience }\end{array}$} & $<5$ years & 36.18 & 9.847 & 11 & \multirow{4}{*}{.676} & \multirow{4}{*}{.574} & \multirow{4}{*}{ NS } \\
\hline & $5-10$ years & 43.20 & 15.834 & 5 & & & \\
\hline & $10-15$ years & 33.25 & 7.136 & 4 & & & \\
\hline & More than 15 years & 35.50 & 12.537 & 10 & & & \\
\hline
\end{tabular}

The association between post test stress score and demographic variables such as Age, Sex, Marital Status, Monthly Family Income, Working area and Total Work Experience of the respondent analysis of variance (ANOVA) had been used with the help of spss 20. The outcome of the analysis in the above table ( 7 ) reveals that there is no association between post test stress score and Age, Sex, Marital Status, Working Area And Total Work Experience of the respondents. $p$ value is greater than 0.05 indicates that there is no significant difference between post test stress score and age, sex, marital status, working area and Total Work Experience of respondents. But there is a significant association between post test stress score and monthly family income because $\mathrm{p}$ value is less than 0.05 .

Testing The Research Hypothesis $\mathrm{H}_{2}$

$\mathrm{H} 2$ - there will be significant association between level of post test stress of staff nurses with the selected demographic variables.

Table 8: Association between selected demographic variables.

\begin{tabular}{|c|l|l|l|}
\hline $\begin{array}{c}\text { Sr. } \\
\text { No. }\end{array}$ & \multicolumn{2}{|c|}{ Asscoation } & Inference \\
\hline 1 & Post test stress score & Age & No association \\
\hline 2 & Post test stress score & Sex & No association \\
\hline 3 & Post test stress score & Marital status & No association \\
\hline 4 & Post test stress score & Monthly family income & Significant association \\
\hline 5 & Post test stress score & Working area & No association \\
\hline 6 & Post test stress score & Total work experience & No association \\
\hline
\end{tabular}

Thus table 8 reveals that there is no significant association between post test stress score of staff nurses with selected demographic variables such as age, sex, marital status, working area and total work experience but there was significant association between post test stress score and monthly family income.

\section{Summary}

This chapter has dealt with the analysis and interpretation of the data Collected from 30 staff nurses. Inferential statistics were used to analyze the data. The analysis has been organized and presented under various sections like description of demographic variables, description of pre-test and post-test stress score, comparison of pre-test and post-test stress score, and association between the post-test stress score and selected demographic variables. 


\section{Discussion \& Conclusion \\ "If you give a man a fish \\ He will have a single meal..... \\ If you teach him how to fish \\ He will eat all his life...!"}

\section{- Khan Tyer}

The present study was conducted to determine the effectiveness of progressive muscle relaxation therapy on stress among staff nurses working in selected hospitals at vadodara city.This chapter discusses the major findings of the study and reviews them in terms of results from other studies.

\section{Objectives Of The Study:-}

To assess the pre-test and post-test level of stress among staff nurses working in selected hospitals at vadodara city.

$>\quad$ To evaluate the effectiveness of the Progressive Muscles Relaxation Therapy on level of stress among staff nurses working in the selected Hospitals at vadodara city.

$>\quad$ To find out the association between the post test stress score with selected demographic variables.

Research Hypothesis

H1 - there will be significant difference in the level of stress before and after administering Progressive Muscle Relaxation Therapy among staff nurses working in selected hospitals at vadodara city.

$\mathrm{H} 2$ - there will be significant association between level of post test stress of staff nurses with the selected demographic variables.

\section{Major Findings Of The Study}

\section{$\begin{array}{lll}1.2 & \text { Section I }\end{array}$}

Description Of Demographic Variables Of Sample

Age categories of the respondents have been divided into four different categories. Among all, $40 \%$ respondents belong to age category of $20-29$ years of age which is the youngest category. $26.7 \%$ respondents belong to the age group of $30-39$ years, while $16.7 \%$ from each of the age group of $40-49$ and 50 -above. Table reveals that among the sample of the study majority of them belongs to the younger age group.

$>\quad$ Sex of the respondents have been depicted, which shows that majority of the respondents are female i.e. $76.7 \%$ of the total sample size, while the representation of male are only $23.3 \%$ in this particular study.

Marital Status of the respondents has been divided into four different categories. Among all, 63.3\% respondents are married. $30.0 \%$ respondents are unmarried, while $3.3 \%$ are widow/ widower. and $3.3 \%$ possessing live in relationship

D Monthly Family Income (in INR) of the respondents have been depicted, which shows that majority of the respondents are having 15001 and above monthly family income i.e. $11 \%$ of the total sample size, while the $10 \%$ of the samples are having monthly family income 10001-15000 . the respondents having monthly family income 5001-10000 are $8 \%$ and only $1 \%$ of the total sample is having monthly family income below 5000 .

Working Area of the respondents has been divided into four different categories. Among that, $33.3 \%$ respondents working in ICU. Majority of the respondents $50 \%$ are working in ward. while $6.7 \%$ are working in casualty and $10 \%$ of the respondents are working in O.T.

Total Work Experience (year ) has been divided into four different categories. Among all majority of the sample are having work experience 5 years and below are $36.7 \%$ while $16.7 \%$ of samples are having work experience $6-10$ years. $13.3 \%$ of the samples are having $11-15$ years of work experience and $33.3 \%$ of the samples are having 16 years and above work experience.

\subsection{Section II}

Analysis And Interpretation Of The Stress Level Of The Sample Collected On Stress assessment rating scale Before And After Administration Of Progressive Muscle Relaxation Therapy.

D The investigator found that during pre tests zero (00\%) samples showing no stress, fourteen $(46.67 \%)$ samples showing mild stress and twelve $(40 \%)$ samples showing moderate stress and four ( $13.33 \%)$ samples having severe stress. After administration of progressive muscle relaxation therapy fifteen (50\%) samples were showing no stress and twelve (40\%) samples showing mild stress and three ( $10 \%$ ) samples showing moderate stress. there is no samples having severe level of stress.

\subsection{Section III}

Evaluate The Effectiveness Of The Progressive Muscle Relaxation Therapy 
It was found that the difference between the mean pre-test (64.17) and post test (36.67) stress scores was found to be significant. The calculated ' $t$ ' value 20.58 was much higher then the tabulated ' $t$ ' value 1.69 at $0.05 \%$ level of significance.

Also the calculated ' $\mathrm{p}$ ' is $>0.000$ which is ideal for any distribution and compared as acceptable 0.05 . so, statistically prove that there was significant difference in stress score of the staff nurses after administering the progressive muscle relaxation therapy.

Hence hypothesis $\mathrm{H} 1$ is accepted.

\subsection{Section IV}

To Find An Association Between Post Test Stress Scores Of The Nurses With Selected Demographic Variables.

$>\quad$ The association between the post test level of stress and demographic variable. The analysis of variance value shows there is no significant association between post test stress score of staff nurses with selected demographic variables such as age, sex, marital status, working area and total work experience but there was significant association between post test stress score and monthly family income.

SUMMARY

This chapter dealt with the discussion of major findings of the study like stress level of staff nurses working in selected hospitals at vadodara city, Effectiveness of progressive muscle relaxation therapy and association between post-test stress score and selected demographic variables.

\subsection{Conclusion}

The study was conducted to assess the effectiveness of progressive muscle relaxation therapy on stress among staff nurses working in selected hospitals at vadodara city. In the present study 30 staff nurses were selected using non probability convenient sampling method.

The findings of the present study showed the mean post-test stress score (36.67) was lower than the mean pretest stress score (64.17). the comparision of level of stress before and after administering the progressive muscle relaxation therapy. It shows that in pre test most of the nurses $53.3 \%$ had moderate stress, $40.0 \%$ had mild stress and $6.7 \%$ had severe stress. In post test most of the nurses had mild stress $73.3 \%$ and no stress $26.7 \%$ stress level.

The comparison of pre-test and post-test stress score showed that there was a significant reduction in stress scores of staff nurses after administration of progressive muscle relaxation therapy .This shows that progressive muscle relaxation therapy was effective.

The study findings concluded that staff nurses had higher stress score before administering progressive muscle relaxation therapy after administering the progressive muscle relaxation therapy the stress score had been reduced.

\subsection{Implication}

The findings of the study have implication for nursing practice, nursing education, nursing administration and nursing research.

\section{Nursing Practice:}

Nurses play a vital and major role in healthcare delivery system and taking measures to prevent psychiatric problems. Community has to be strengthened by emphasizing health education and awareness programmes.

Nurses working in hospitals as well as community should know taking care of clients with acute or chronic illness to prevent psychiatric morbidity.

Early identification and intervention prevents stress -related physical and psychosocial problems. Progressive Muscle Relaxation Therapy is an inexpensive intervention in order to reduce stress.

The nurses can provide awareness to the people regarding this intervention.

The findings of this study indicate that there is a need for Progressive Muscles Relaxation Therapy for clients who are affected by Stress.

From the present study it was found that Progressive Muscles Relaxation Therapy was an effective stress reduction method.

The investigator as a nurse felt that nurses should have skill regarding various therapies other than medicine to help the clients and families to relieve their stress which in turn helps in preventing psychiatric illness and making their life more hopeful even though affected by illness.

\section{Nursing Education:}


The healthcare delivery system at present gives more emphasis on preventive rather than curative aspect. The study also implies that health personnel have to be aware of the various methods of stress reduction for prevention of stress rather than giving medicines. The established effectiveness of Progressive Muscles Relaxation Therapy can be used to teach as a stress reduction method to student nurses, patients, and caregivers of clients. Nursing students should be trained to acquire skill in assessing the stress of clients in different settings and to intervene with the appropriate literature so that they can be prevented from taking anti depressive other medicines to relieve their stress. Today's nurses are extending their role to different areas other than caring for the sick in hospitals. Many nurse practitioners are interested in independent interventions. The Progressive Muscles Relaxation Therapy is an independent intervention which can be used by nurses according to the needs of the client.

\section{Nursing Research:}

Usage of Progressive Muscles Relaxation Therapy in clinical practice is relatively an unexplored area as far as India is concerned. Many more research studies could be done to assess the efficacy of this highly feasible and less expensive therapy in various other conditions and settings. The present study is just an initial attempt and it will encourage and motivate health personnel to do many more research studies in this area. The researchers can also explore similar therapies which increase the self-confidence and self-worth of sample. Future investigators can use the findings and the methodology as reference material.

\section{Nursing Administration:}

The administrative nursing can also provide training of Progressive Muscles Relaxation Therapy for staff nurses, student nurses, and other allied profession. The nurse authors should take a keen interest in Progressive Muscles Relaxation Therapy for the effective use in various areas like clinical practice, community, and home

Health care.

\section{Recommendations For Further Study:}

The study can be conducted for larger sample size which will facilitate more reliable result.

$>\quad$ A similar study can be conducted in different settings.

$>\quad$ The experimental study can be conducted to find out the effectiveness of Progressive Muscles Relaxation Therapy on stress among caregivers of mentally ill patient.

$>\quad$ The effectiveness of Progressive Muscles Relaxation Therapy in reducing stress among cancer patients admitted in hospitals.

$>\quad$ A similar study can be conducted to find out the Stress and coping strategies of hospice nursing.

$>\quad$ A comparative study can be conducted to find out the level of stress among staff nurses working in the selected government and private hospitals.

$>\quad$ A similar study can be done with large sample size.

$>\quad$ A similar study can be conducted to find out the level of stress among staff nurses working in the Mental Health Hospitals and General Hospitals.

\section{Summary}

Ability is what you are capable of doing,

Motivation determines what to do,

Attitude determines how well you do it....

- Lun Heltz

An evaluative research approach was used to determine the effectiveness of Progressive Muscle Relaxation Therapy on stress among staff nurses working in selected hospitals at vadodara city.

\section{Objectives:}

The objectives of the study were,

To assess the pre-test and post-test level of stress among staff nurses working in selected hospitals at vadodara city.

$>\quad$ To evaluate the effectiveness of the Progressive Muscles Relaxation Therapy on level of stress among staff nurses working in the selected Hospitals at vadodara city.

$>\quad$ To find out the association between the post test stress score with selected demographic variables.

\section{Research Hypothesis}

H1 - there will be significant difference in the level of stress before and after administering Progressive Muscle Relaxation Therapy among staff nurses working in selected hospitals at vadodara city. 
$\mathrm{H} 2$ - there will be significant association between level of post test stress of staff nurses with the selected demographic variables.

Quantative research approach with pre-experimental design was used and the study was conducted at selected hospitals in vadodara city. The sampling technique used was non - probability convenient sampling. Data collection was done using the baseline Performa, stress assessment rating scale. A pilot study was conducted from 20-10-2013 to 28-10-2013 to assess the feasibility. The investigator obtained written consent from the concerned authority before the study.

The conceptual framework used for this study was based on Ludwing Von Bertanloffy's general system theory model.

Data collection was done from 8-11-2013 to 24-11-2013. Sample of the study was 30 staff nurses. Analysis of the obtained data was planned based on the objective and hypotheses of the study .Both descriptive and inferential statistics were used for data analysis. Descriptive statistics used were frequency, mean, range and standard deviation. The data was also presented graphically. Comparison between the pre-test and post-test scores were obtained by paired't' test. To test the hypotheses the level of significance was set at 0.05 level of significance.

Major findings of the study

Age categories of the respondents have been divided into four different categories. Among all, $40 \%$ respondents belong to age category of $20-29$ years of age which is the youngest category. $26.7 \%$ respondents belong to the age group of $30-39$ years, while $16.7 \%$ from each of the age group of $40-49$ and 50 - above. Table reveals that among the sample of the study majority of them belongs to the younger age group.

$>\quad$ Sex of the respondents have been depicted, which shows that majority of the respondents are female i.e. $76.7 \%$ of the total sample size, while the representation of male are only $23.3 \%$ in this particular study.

Marital Status of the respondents has been divided into four different categories. Among all, 63.3\% respondents are married. $30.0 \%$ respondents are unmarried, while $3.3 \%$ are widow/ widower. and $3.3 \%$ possessing live in relationship

$>$ Monthly Family Income (in INR ) of the respondents have been depicted, which shows that majority of the respondents are having 15001 and above monthly family income i.e. 11\% of the total sample size, while the $10 \%$ of the samples are having monthly family income 10001-15000 . the respondents having monthly family income 5001-10000 are $8 \%$ and only $1 \%$ of the total sample is having monthly family income below 5000 .

$>\quad$ Working Area of the respondents has been divided into four different categories. Among that, $33.3 \%$ respondents working in ICU. Majority of the respondents $50 \%$ are working in ward. while $6.7 \%$ are working in casualty and $10 \%$ of the respondents are working in O.T.

$>$ Total Work Experience (year) has been divided into four different categories. Among all majority of the sample are having work experience 5 years and below are $36.7 \%$ while $16.7 \%$ of samples are having work experience $6-10$ years. $13.3 \%$ of the samples are having $11-15$ years of work experience and 33.3 $\%$ of the samples are having 16 years and above work experience.

$>$ The investigator found that during pre tests zero (00\%) samples showing no stress, fourteen $(46.67 \%)$ samples showing mild stress and twelve (40\%) samples showing moderate stress and four $(13.33 \%)$ samples having severe stress. After administration of progressive muscle relaxation therapy fifteen $(50 \%)$ samples were showing no stress and twelve (40\%) samples showing mild stress and three ( $10 \%)$ samples showing moderate stress. there is no samples having severe level of stress.

$>\quad$ It was found that the difference between the mean pre-test (64.17) and post test (36.67) stress scores was found to be significant. The calculated ' $t$ ' value 20.58 was much higher then the tabulated ' $t$ ' value 1.69 at $0.05 \%$ level of significance.

$>$ Also the calculated ' $\mathrm{p}$ ' is $>0.000$ which is ideal for any distribution and compared as acceptable 0.05 . so, statistically prove that there was significant difference in stress score of the staff nurses after administering the progressive muscle relaxation therapy.

$>\quad$ The association between the post test level of stress and demographic variable. The analysis of variance value shows there is no significant association between post test stress score of staff nurses with selected demographic variables such as age, sex, marital status, working area and total work experience but there was significant association between post test stress score and monthly family income.

The result of the study showed that the progressive muscle relaxation therapy was helpful to lower the stress of staff nurses. 


\section{References}

[1]. Beddoe AE, Murphy SO. Does mindfulness decrease stress and foster empathy among nursing students? J Nurs Educ. 2004;43(7):305-12. [PubMed]

[2]. Taghavi Larijani T, Ramezani Badr F, Khatoni A, Monjamed Z. Comparison of stressors in the final year students of nursing and midwifery selected University of Tehran. Journal of Nursing and Midwifery, Tehran University of Medical Sciences (Hayat) 2007;13(2):61-70.

[3]. Abazari F, Abaszadeh A, Arab M. Evaluation and sources of stress in nursing students. Journal of Medical Education Development steps. 2004;1(1):23-31.

[4]. Shipton SP. The process of seeking stress-care: coping as experienced by senior baccalaureate nursing students in response to appraised clinical stress. J Nurs Educ. 2002;41(6):243-56. [PubMed]

[5]. Gammon J, Morgan-Samuel H. A study to ascertain the effect of structured student tutorial support on student stress, self-esteem and coping. Nurse Educ Pract. 2005;5(3):161-171. [PubMed]

[6]. Ryan ME TR. Concerns, values, stress, coping, health and educational outcomes of college students who studied abroad. International Journal of Intercultural Relations. 2000;24(2000):409-35.

[7]. Akochekian Sh, Rohafza HR, Hasanzadeh A, Mohammad Shrifi H. Associated with social support coping strategies in a psychiatric ward nurses. Journal of Medical SciencesGilan. 2008;18(69):41-6.

[8]. Dehghan Nayeri N, Adib Hajbagheri M. Stress relaxation effect on quality of life and resident students in student dormitories. Journal - Research Feyz. 2006;10(2):50-70.

[9]. Forozandeh N, Delaram M. Effect of cognitive behavioral therapy on coping methods non-medical student university of medical sciences. Shahre Kord University of Medical Sciences Journal. 2003;5(3):26-34

[10]. Kaviani H, Pournaseh M, Sayadlou S, Mohammadi MR. Effectiveness of stress management training in reducing anxiety and depression, participants in class exam. New Journal of Cognitive Sciences. 2007;8(2):61-8.

[11]. Eby L, Brown NJ. mental health nursing care. In: Elder R, Evans K, Nizette D, editors. psychiatric and mental health nursing. Sydney: Elsevier, Mosby; 2009. p. 68.

[12]. Daubenmier JJ, Weidner G, Sumner MD, Mendell N, Merritt-Worden T, Studley J, et al. The contribution of changes in diet, exercise, and stress management to changes in coronary risk in women and men in the multisite cardiac lifestyle intervention program. Ann Behav Med. 2007;33(1):57-68. [PubMed]

[13]. Edwards D, Burnard P, Ben Hannigan MA, Copper L, Adams J, JuggessurT et al. Clinical supervision and burnout: the influence of clinicalsupervision for community mental health nurses. J Clin Nurs.2006;15(8):1007-15.

[14]. Ibrahim Humaida, "Relationship between Stress and Psychosomatic Complaints among Nurses in Tabarjal Hospital," Open Journal of Medical Psychology, Vol.1 No. 3, 2012, pp.15-19. doi:10.4236/ojmp13003. 2012

[15]. Karick H et al. An evidence-based empirical study. The role of stress and level of burnout in job performance among nurses on Nigerian nurses.September 2011 Available from: ProQuest Dissertations;2011

[16]. .http://www.camcommons.org/progressive-muscle-relaxation-as-an-evidence-based-cam-treatment.html

[17]. Cathy Wong. Health's Disease and Condition Medical Review Board, February 17, 2011; Available from: About.com/ http:altmedicine.about.com - old-treatments/remedies-a-benefits-ofprogressive-muscle-relaxation.htm, About.com.

[18]. .http://www.indianjournals.com/ijor.aspx ?target $=$ ijor:ijone $\&$ volume $=5 \&$ issue $=2 \&$ article $=036$

[19]. .LudwigVonBertalanffy.GeneralSystemTheory.Available from:http://webhostinggeeks.com/science/ludwig-von-bertalanffy.

[20]. Deependra Singh Kushwah. Descriptive and Exploratory study to assess occupation stress, Dhanwantari Nursing College Bangalore, Karnataka;2011.

[21]. Mr. M. Joy. A comparative study to assess the level of occupational stress among staff nurses working in the day shift with that of night shift in selected hospitals at Mangalore,' Masood College of Nursing, Mangalore;2011

[22]. Ningthoujam Monalisa Chanu. A study to assess the effectiveness of structured teaching programme on stress and coping among caregivers of hospitalized patients in a selected psychiatric hospital in Bangalore, RGUHS, Banglore;2011

[23]. Nirmanmoh Bhatia et al. Occupational Stress amongst nurses from Two Tertiary Care Hospitals in Delhi, India. January 2011, AMJ;3(11)-731-738 Availablefrom:www.amj. com.

[24]. Beverly J. Myers. Organizational support, perceived social support, and intent to turnover among psychiatric nurses;2006. Available from: Udini ProQuest LLC

[25]. Hsu HY, Chen SH, Job stress, achievement motivation and occupational burnout among nurses Journal Taiwan Nurses. 2010 May [Cited 2010, Jul 6] Available from:e-pub1592-601

[26]. Urmila Rani Srivastava. Shift Work Related to Stress, Health and Mood States. Department of Psychology, Banaras University, Varanasi, India. Email:urbhu_24@yahoo.co.in

[27]. Eleni Moustaka, Sources and effects of Work-related stress in nursing. Health Science Journal. 2010-volume-4(4). Availablefrom:

[28]. E-mail: emoustaka73@yahoo.com

[29]. Kane PP. Stress causing psychosomatic illness among nurses; IndianJournal of Occupational Env. Medicine;2009;Apr;13-1- 28-32.

[30]. Christopher Sudhaker. Job Stress, Coping Strategies and the Job Quality Index of Nurses Working In Selected Multi Specialty Hospitals at Mangalore. December 2009. Available from:http//www.pubmaid.in.com[56832189]

[31]. Dr MI Nor Azlin. A descriptive study aimed to prevalence of stress and coping mechanism among staff nurses in the Intensive Care Unit at Kebangsaan, Malaysia.University Kebangsaan, Malaysia Medical Centre, 56000 Kuala Lumpur. Tel:03-91455949,Fax;60391738946.2006;

[32]. Availablefrom:www.hukm.ukm.my/azlin.com

[33]. Richard A. White, Perceived stressors, coping strategies, and burnout pertaining to psychiatric nurse working on locked psychiatric units. Masters ThesesandDoctoralDissertations.2006;Paper-84. http://commons.emich.edu/theses/2006(84)

[34]. Atish Taukari and Tanmay Bhattacharya, Occupational Stress and Coping among Nurses; Department of Humanities and Social Sciences, Indian Institute of Technology Mumbai 400076 Available from: www.iitindia.org

[35]. Purvi J. Parikh et al, "Occupational Stress and Coping among Nurses" - Department of Humanities and Social Sciences, Indian Institute of Technology, Bombay, Powai, Mumbai.

[36]. http://move2wellness.com/relaxation-technique-3-progressive-muscle-relaxation-for-stress-relief/

[37]. Nayak H K, And Tiwari H. et al. Prevalence and pattern of stress relaxation practices in Ahmedabad. A cross-sectional study International Journal of Yoga, online Year: 2011;-Volume:4(2)-87- 92.[cited 2012 June25]; Available from: www.internationaljournalofyoga[4(2):2012.

[38]. http://www.hsj.gr/volume5/issue2/521.pdf

[40]. Gregory E. Harris. Relaxation Techniques; Adult Literacy and Learning Disabilities: Best Practices for Success, University of Calgary, Division of Applied Psychology;2010-Section 10 
[41]. Ghafari S. et al. Effectiveness of applying Progressive Muscle Relaxation Technique on quality of life. Department of Nursing, University of Medical Science,Fasa,Iran.August2009;Availablefrom:www.universityofmedicalscience,fasa,iran.org

[42]. Max G Feirstein. Moderation effects of absorption and worry on group-induced relaxation states. A Pre-experimental investigation. Available from: ProQuest Dissertations and Theses;2009

[43]. Ohmori F, Shimizu S. \& Kagaya A. Exercise-induced blood flow in relation to musclerelaxationperiod.2007-Vol6Availablefrom: About.com/http:altmedicine.about.com

[44]. http://119.82.96.198:8080/jspui/bitstream/123456789/1509/1/CDNNPSY00022.pdf

[45]. Conrad, A. \& Roth, WT. Muscle relaxation therapy for anxiety disorders: It works but how? Journal of Anxiety Disorders;2006; volume -21-243-264

[46]. De Berry S. An evaluation of progressive muscle relaxation on stress related symptoms in a geriatric population . Int J Aging Hum Dev . 1981;14:255-269

[47]. Edmund Jacobson. Treatment efficacy of Progressive Muscle Relaxation Technique; - A relaxation technique of stress management, Journal of American Physician; 34 ;vol;XX;9

[48]. http://synapse.koreamed.org/DOIx.php?id=10.5124/jkma.2013.56.6.478

[49]. http://nccam.nih.gov/health/stress/relaxation.htm

[50]. http://psycnet.apa.org/journals/str/19/1/48/International Journal of Stress Management, Vol 19(1), Feb 2012, 48-68. doi: $10.1037 / \mathrm{a} 0027326$

[51]. http://www.webmd.com/balance/stress-management/stress-management-doing-progressive-muscle-relaxation\#

[52]. Iranian journal of nursing and midwifery res:2010,Autumn; 15(4) : 208-215 PMCID: PMC3203278

[53]. calicut medical journal 2007: 5(2):ez

[54]. http://www.ncbi.nlm.nih.gov/pmc/articles/PMC2268875/

[55]. http://www.medicinenet.com/script/main/art.asp?articlekey=47281

[56]. Taehan kanho Hakhoe chi 2004 Apr; 34 (2):213-24 